\title{
Las estelas del Suroeste en el valle del Guadalquivir y Sierra Morena: distribución espacial y nuevas perspectivas de investigación
}

\author{
Late Bronze Age stelae in the Guadalquivir valley and Sierra Morena: spatial distribution \\ and new perspectives of research
}

Manuel Eleazar Costa Caramé (*)

\section{RESUMEN}

En este artículo se analiza la distribución espacial de las estelas de la Edad del Bronce Final en dos zonas del Suroeste de la Península Ibérica con el fin de contrastar algunas de las hipótesis que se han defendido sobre su posible función como hitos o marcadores territoriales. Se evalúa la posible relación entre la distribución de estos monumentos y determinadas variables geográficas y arqueológicas. Los resultados obtenidos han sido de gran utilidad para valorar la validez de algunas de las hipótesis defendidas, así como las carencias y limitaciones de la información disponible y de los análisis espaciales llevados a cabo.

\begin{abstract}
This paper focuses on the spatial distribution of Late Bronze Age stelae in two geographical areas from Southwest of the Iberian Peninsula in order to test many of the hypotheses which have been proposed according to their possible functionality as territorial markers. An evaluation has been made according to the possible relation between the distribution of these monuments and some geographical and archaeological variables. The results obtained have been very useful to test some of the existing interpretations from a spatial approach and to evaluate the limitations of the present information and of the spatial analysis carried out.
\end{abstract}

(*) ATLAS Arqueología y Patrimonio S. L. C/ Juan Rabadán 19B. 41002 Sevilla.

Correo e.: eleazarcosta@atlasarqueologia.es

Recibido 20-II-2012; aceptado 28-V-2012.
Palabras clave: Estelas grabadas; Edad del Bronce Final; Edad del Hierro; Prehistoria Reciente; Arqueología espacial; Sistema de Información Geográfica; Estadística.

Key words: Carved stelae; Late Bronze Age; Iron Age; Recent Prehistory; spatial archaeology; GIS; Statistics.

\section{INTRODUCCIÓN}

La investigación sobre las estelas de la Edad del Bronce Final del Suroeste de la Península Ibérica es un tema sobre el que a día de hoy existe una bibliografía extensa que incluye trabajos monográficos de gran difusión (Galán Domingo 1993; Celestino Pérez 2001; Harrison 2004; Díaz-Guardamino Uribe 2010). Este interés podría deberse al hecho de que la información de las estelas, junto con los depósitos de armas y los hallazgos de tesoros, ha sido frecuentemente empleada para reconstruir la organización social del Bronce Final, dada la escasez de datos del registro funerario y habitacional de este período (Celestino Pérez et al. 2012).

Según las obras referidas, las estelas del Suroeste son monumentos en piedra en cuya superficie se grabaron imágenes de artefactos, generalmente armas y adornos, figuras antropomorfas y en algunos casos zoomorfas (Fig. 1). La mayoría aparecieron en el transcurso de labores agrícolas entre los años 1955 y 1960 sin supervisión arqueológica, motivo por el cual se desconoce su lugar exacto de hallazgo y normalmente se ha considerado que podrían estar descontextualiza- 
das. Tradicionalmente han sido datadas en la Edad del Bronce Final (c. 1250-850 B.C.) en base a la morfología de los objetos representados. Sin embargo, enfoques recientes han puesto énfasis en una cronología de larga duración que comenzó en la Edad del Bronce Final y continuó hasta la Edad del Hierro e incluso períodos posteriores (Celestino Pérez et al. 2012; Díaz-Guardamino Uribe 2012). En caso de que su uso y reutilización pudiese haber tenido tal diacronía es bastante posible que las estelas hubiesen adquirido una simbología diferente de acuerdo con los diferentes contextos socioeconómicos de cada período (Celestino Pérez et al. 2012; Díaz-Guardamino Uribe 2010, 2012). Este hecho tiene importantes repercusiones ya que dificulta su estudio como un fenómeno cultural simple e unívoco. La problemática referida no es tan solo exclusiva de las estelas consideradas en este artículo, sino que también afecta a otros monumentos de cronología similar hallados en otras áreas de la Península Ibérica, como las estelas-menhir del noroeste peninsular (FábregaÁlvarez et al. 2011).

Desde el primer estudio de conjunto (Almagro Basch 1966) las monografías se han ido actuali-

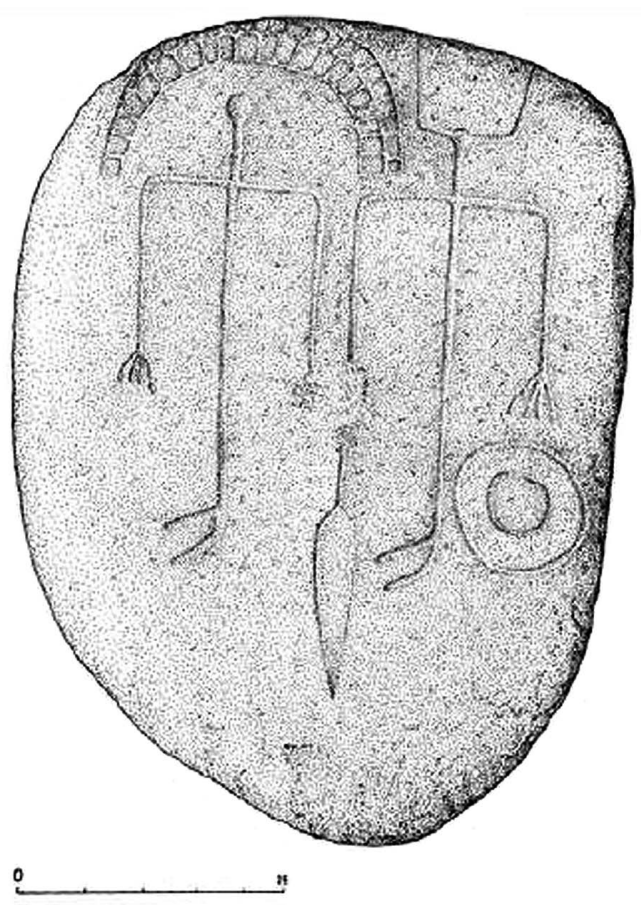

Fig. 1. Estela hallada en Almadén de la Plata (Sevilla). Según García Sanjuán et al. 2006. zando progresivamente a medida que han aparecido nuevos ejemplares (Celestino Pérez 2001; Harrison 2004; Domínguez de la Concha et al. 2005; Murillo Redondo et al. 2005; García Sanjuán et al. 2006). A día de hoy se conocen entre 110 y 120 , aunque se ha considerado que podrían existir en torno a unos 114 monumentos (García Sanjuán 2010: 2).

La funcionalidad de las estelas ha sido en el pasado, y continúa siendo en la actualidad, objeto de una amplia controversia y de un intenso debate en el panorama epistemológico de la arqueología española, sin que por el momento exista ningún acuerdo entre los investigadores. Su consideración inicial como monumentos funerarios (Almagro Basch 1966) sigue vigente a día de hoy (Celestino Pérez 2001: 279) y se ha argumentado en base a su iconografía, a la morfología y a la composición de los motivos representados. No obstante algunos investigadores han señalado la ausencia de una asociación directa entre las estelas y estructuras funerarias o áreas de demostrada significación funeraria (Harrison 2004: 34; García Sanjuán 2010: 5). Recientemente se han documentado varias en contextos funerarios posiblemente datados en la Edad del Hierro, período en el cual las estelas habrían sido reutilizadas dentro de un contexto social, económico y simbólico bastante diferente al existente durante la Edad del Bronce Final (Díaz-Guardamino Uribe 2012: 402). E1 análisis basado en los precedentes arqueológicos parece haber demostrado que la asociación de las estelas a lugares funerarios podría ser consistente con la tradición funeraria documentada desde el Neolítico, basada en la realización de pinturas o grabados en monumentos funerarios (García Sanjuán 2010: 3). Esta hipótesis ha sido también defendida para las iconografías grabadas (Díaz-Guardamino Uribe 2012). Asimismo, se ha argumentado la correspondencia entre los objetos representados en estos soportes y los existentes en el pasado (Galán Domingo 2008: 8), aunque por el momento muchos de ellos no han sido encontrados en el registro arqueológico de la Edad del Bronce Final (García Sanjuán 2010: 2) ni tampoco en el registro funerario de este período, bastante mal conocido en todo el Suroeste peninsular salvo determinadas excepciones.

La composición de los grabados de las estelas ha servido para definir su agrupación y distribución geográfica según las coordenadas de 
su zona de hallazgo (Celestino Pérez y Salgado Carmona 2011; Celestino Pérez et al. 2012), su evolución cronológica, su origen y su posterior expansión a otras áreas peninsulares (Celestino Pérez 2001). Otros investigadores han relacionado las diferencias en la composición de los elementos iconográficos con aspectos ideológicos o funcionales (García Sanjuán 2010: 3). Asimismo varios trabajos han analizado los motivos grabados mediante técnicas estadísticas multivariantes y las diferentes agrupaciones de acuerdo con su distribución y composición (Barceló Álvarez 1991; Galán Domingo 1993). Aunque se han obtenido resultados bastante limitados en cuanto a su interpretación, lo cierto es que estos han supuesto la aplicación de nuevas metodologías de análisis.

En las últimas décadas, algunos investigadores han priorizado el estudio contextual de las estelas dentro de su área de aparición (Galán Domingo 1993) en detrimento de los motivos representados (Celestino Pérez y Salgado Carmona 2011: 423). Ello se debe a la hipótesis de su uso como posibles marcadores territoriales ubicados en lugares de paso o en relación con rutas ganaderas (Galán Domingo 1993: 28-30; García Sanjuán et al. 2006: 149). Una función similar se ha defendido para los depósitos metálicos del Bronce Final hallados en contextos acuáticos (Ruiz-Gálvez Priego 1995). Estas interpretaciones han dejado de considerar a las estelas como monumentos descontextualizados para valorar su función como elementos empleados en la construcción cultural del paisaje. Desde el punto de vista de los precedentes arqueológicos parece que las estelas del Suroeste podrían ser contextualizadas dentro de la tradición de los monumentos megalíticos peninsulares, a los que también se les ha asignado una posible función como marcadores territoriales (García Sanjuán 2010: 6; Murrieta Flores et al. 2009). Se ha demostrado, por ejemplo, que podría haber existido una relación consistente entre la ubicación de la estela hallada en Almadén de la Plata (Sevilla) y la ruta ganadera del Cordel del Pedroso, datada en época medieval y con posibles orígenes anteriores (Murrieta Flores et al. 2009; García Sanjuán 2010: 10). Este resultado, que tendría importantes repercusiones en lo que se refiere a la posible funcionalidad territorial de las estelas, es bastante similar a los obtenidos en otros estudios espaciales efectuados por medio de sistemas de información geográfica, tanto para algunas de las estelas incluidas en este estudio (Celestino Pérez et al. 2012), como para monumentos de cronología similar de otras áreas peninsulares (FábregaÁlvarez et al. 2011).

Recientemente Harrison (2004: 35) ha vuelto a resaltar la función simbólica e ideológica de estos monumentos y ha criticado la posibilidad de que fueran empleados como elementos de organización del territorio. En este contexto epistemológico parece que el acuerdo entre los investigadores está lejos de alcanzarse, ya que a día de hoy faltan evidencias claras e inequívocas que permitan solventar la controversia existente.

Las referencias a la función de las estelas como marcadores territoriales son frecuentes en aquellas publicaciones que han estudiado este aspecto, aunque lo cierto es que a día de hoy son escasos los trabajos de investigación que han aplicado una metodología formalizada de estudio espacial a estos monumentos (Murrieta Flores et al. 2009; García Sanjuán 2010; Celestino Pérez et al. 2012). Galán Domingo (1993), por ejemplo, evaluó variables geográficas como la distancia de las estelas a los principales ríos y a las rutas ganaderas o la relación entre las mismas y la calidad del suelo, aunque en este caso dichos análisis no se efectuaron por medio de un sistema de información geográfica. Algunas de las interpretaciones sobre la dimensión territorial y paisajística de las estelas tienen un gran interés a nivel teórico, pero no pueden ser consideradas estadísticamente consistentes. Actualmente una bibliografía amplia sobre este tipo de técnicas en arqueología (Hodder y Orton 1989; Wheatley y Gillings 2002; Conolly y Lake 2006) permite contrastar muchas de las interpretaciones defendidas en los últimos años sobre su distribución espacial. En resumen se puede decir que, salvo excepciones, no hay estudios espaciales sólidos que permitan identificar posibles pautas espaciales en la distribución de las estelas en relación con las diferentes variables de la geografía natural o humana. En este contexto este estudio pretende llevar a cabo un análisis espacial que siente las bases para futuros trabajos de investigación sobre estelas, así como fomentar el debate y enriquecerlo desde nuevos puntos de vista. 


\section{INFORMACIÓN ESPACIAL} DE LAS ESTELAS Y METODOLOGÍA EMPLEADA

Si se tiene en cuenta la distribución de las estelas en la Península Ibérica se observa que existe una mayor concentración de monumentos en cuatro zonas (Celestino Pérez 2001): la sierra de Gata (zona 1), el valle del Tajo y la sierra de Montánchez (zona II), los valles del Guadiana y del Zújar (III) y el valle del Guadalquivir (IV) (Celestino Pérez 2001: 48-59). A su vez, parece haberse demostrado que las estelas tienen unas características compositivas propias de acuerdo con los motivos representados y el área de hallazgo (véase Celestino Pérez et al. 2011: 91-96). Dado que esta investigación se centra en el análisis espacial y no en el estudio de los motivos representados, se han omitido las diferencias compositivas a nivel figurativo señaladas, empleándose la zona geográfica de hallazgo como unidad de análisis. A pesar de ello, sería conveniente que en el futuro se efectuase un análisis espacial de conjunto que tuviera en cuenta los motivos figurativos y que permitiera contrastar los resultados obtenidos. Dada la complejidad de dichos datos y la necesidad de que se efectúe un análisis amplio, resulta imposible incluir esa información en este artículo.

La información arqueológica existente en el Suroeste no es homogénea y está fuertemente influída por la investigación llevada a cabo en cada área, hecho que dificulta la realización de un estudio comparativo. Con el objetivo de solventar este problema se han seleccionando 44 estelas (Fig. 2) encontradas en el valle del Guadalquivir y en Sierra

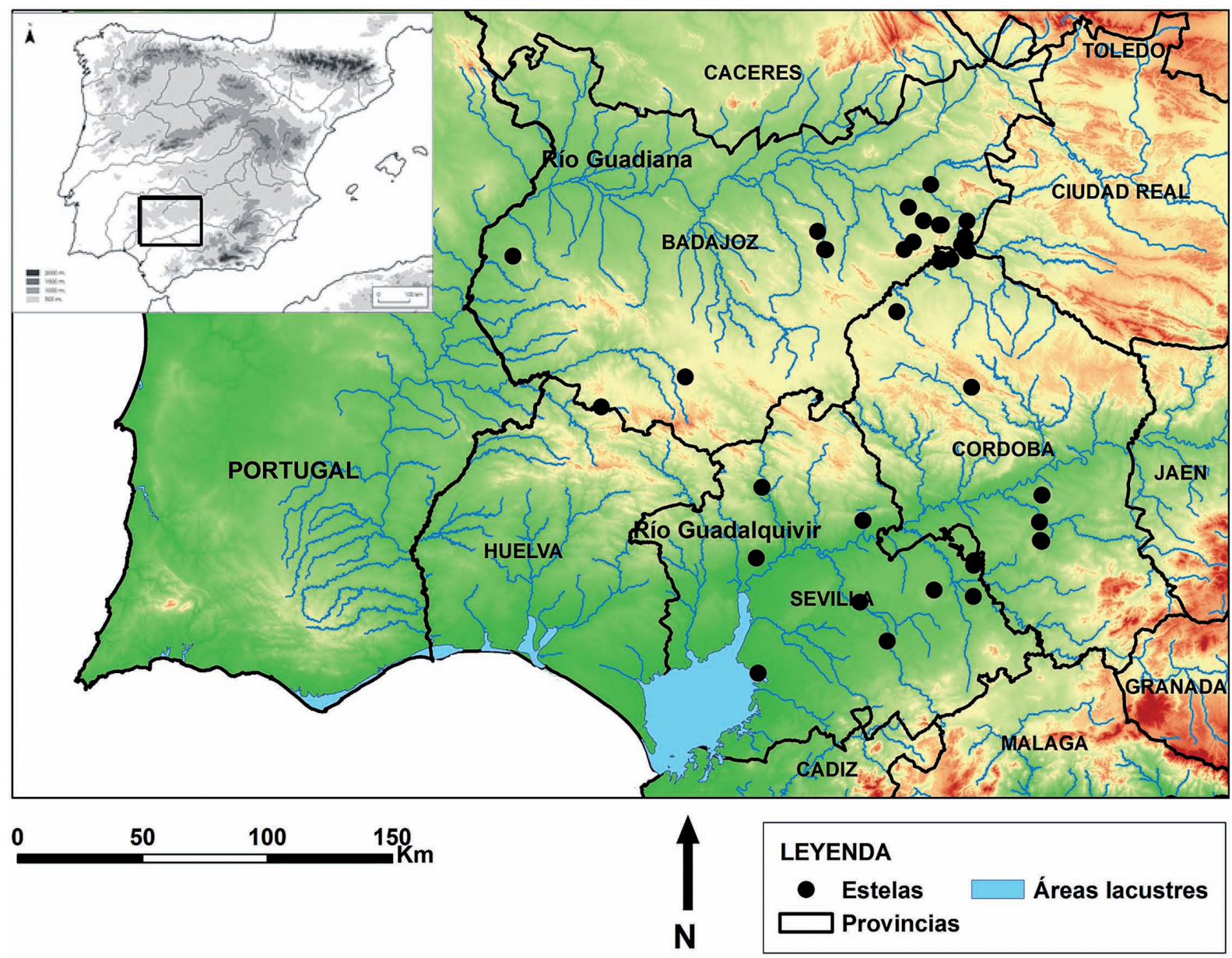

Fig. 2. Distribución de las estelas en el Suroeste peninsular. 
Morena (provincias de Sevilla, Córdoba y Badajoz) (Tab. 1, Fig. 3).

Los 10 monumentos procedentes del valle del Guadiana han sido excluidos de este estudio, debido a que solo se conoce la ubicación geográfica de 6 de ellos. Este número reducido impide efecturar un análisis comparativo con las otras áreas seleccionadas. Las estelas escogidas suponen el 38\% de las 114 documentadas en la última compilación publicada (Harrison 2004). No obstante en los últimos años se han producido nuevos hallazgos (Murillo Redondo et al. 2005; García Sanjuán et al. 2006), y otros investigadores consideran que su número podría superar los 120 ejemplares (Celestino Pérez et al. 2012: 136).
La falta de información precisa sobre el lugar de hallazgo de las estelas ha sido empleada como argumento para defender su descontextualización total. A pesar de que estos monumentos fueron desplazados de su localización original por labores agrícolas sin control arqueológico, son demasiado pesados para ser transportados a más de un centenar de metros de la misma (Galán Domingo 1993: 31). Por lo tanto, resulta imposible identificar las coordenadas exactas de su lugar de hallazgo pero se puede conocer su área aproximada de ubicación. En este contexto es posible aplicar técnicas de análisis espacial, así como contrastar algunas de las hipótesis que se han defendido sobre su posible funcionalidad territorial.

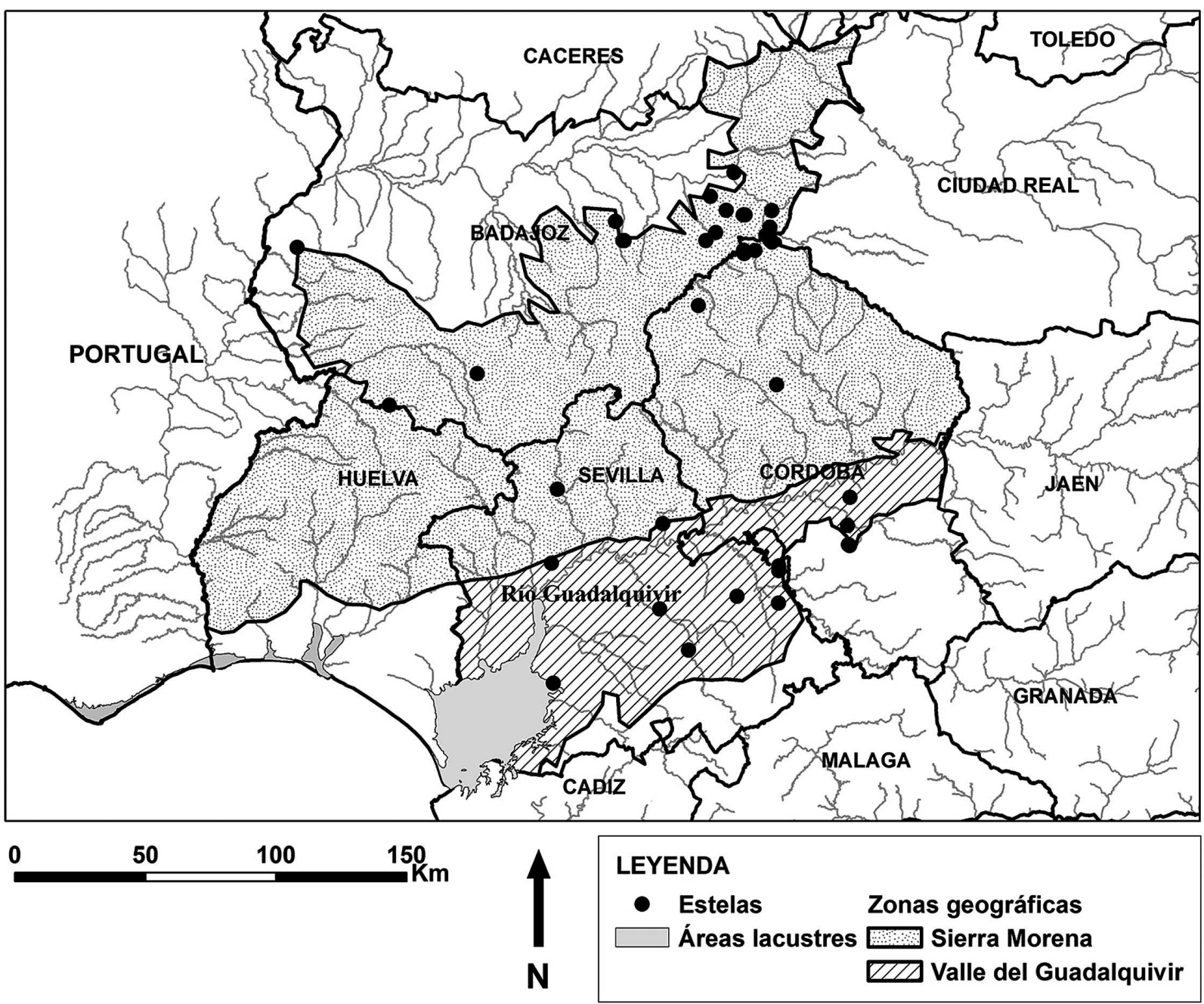

Fig. 3. Áreas geográficas seleccionadas para el estudio de las estelas del Suroeste de la Península Ibérica.

Trab. Prehist., 70, N. ${ }^{\circ}$ 1, enero-junio 2013, pp 76-94, ISSN: 0082-5638 doi: $10.3989 /$ tp.2013.12103 
Galán Domingo (1993) y Celestino Pérez (2001) georreferenciaron el lugar de hallazgo de las estelas con coordenadas geográficas. Sin embargo, la reutilización posterior de estos monumentos podría haberlas desplazado de su ubicación original, siendo menor el traslado en las antiguas que en las modernas (Celestino Pérez et al. 2012: 139). Varios trabajos han intentado evaluar la posible cronología de las estelas y su grado de reutilización (Díaz-Guardamino Uribe 2010, 2012) sin que por el momento sea posible estimar su grado de remoción, ni de desplazamiento en términos cuantitativos. A su vez estos resultados parecen indicar un mayor desplazamiento de las estelas que podrían haber sido reutilizadas con fines simbólicos funerarios o constructivos en la antigüedad, como por ejemplo las de Cancho Roano, Capote (Zalamea de la Serena e Higuera la Real, Badajoz) o Setefilla (Lora del Río, Sevi1la). Algunos investigadores han hecho hincapié en que, si se emplease una escala de análisis superior a la del margen de error de las coordenadas geográficas del lugar de hallazgo, se podría minimizar el efecto de la distorsión producida por el mismo en el estudio espacial (Celestino Pérez et al. 2012: 141). Esto permitiría aplicar análisis espaciales a escala macro espacial, aunque no a escala semi-micro o micro, donde todos los análisis basados en puntos resultan problemáticos por su margen de error (Celestino Pérez et al. 2012: 141). A pesar de ello, hay que recordar que, al ser monumentos de gran peso, es muy probable que no fueran movidos de su lugar original más allá de unos centenares de metros o incluso menos (Galán Domingo 2003: 31), por lo que las coordenadas aproximadas podrían ser empleadas para un estudio espacial. Esta situación ha sido confirmada donde se ha podido llevar a cabo una prospección intensiva en el área de hallazgo (Celestino Pérez et al. 2012: 147) y cuando esta información ha sido complementada con un estudio petrográfico para ver la procedencia de la materia prima (García Sanjuán et al. 2006). La imprecisión en la localización de las estelas afecta a todos estos monumentos y debido a que no se pueden diferenciar grupos o poblaciones que tengan un margen de error similar, o al menos no tenemos datos para valorar esta variable. Por ello parece posible aplicar un análisis espacial aproximativo, al menos a escala macro espacial, con el objetivo de refutar o confirmar algunas de las hipótesis existentes sobre su distribución espacial. Una situación similar se ha documentado en otros estudios espaciales donde se partía del problema de cómo aplicar análisis a capas de puntos con datos con cierto margen de error, probabilidad o imprecisión, como por ejemplo sucede con la información de las dataciones radiocarbónicas (Crema et al. 2010).

A fin de crear una base de datos de coordenadas geográficas homogénea y coherente, fundamental para llevar a cabo un estudio sistemático, se han descartado los análisis de monumentos cuya procedencia se desconoce. Todas las coordenadas de los trabajos indicados (Galán Domingo 1993; Celestino Pérez 2001) se han convertido a la proyección UTM, Europeam Datum 1950, Elipsoide de Hayford, Zona 30 (Tab. 1).

Como técnica estadística se ha aplicado el test de Kolmogorov-Smirnov que identifica si una distribución clasificada en escalas tiene una distribución normal o no y compara la probabilidad de la semejanza de dos distribuciones. En el estudio espacial, siguiendo a Wheatley y Gillings (2002: 140), este test se ha empleado con un nivel de confianza de 0,05 para ver si existe alguna relación estadísticamente significativa entre la distribución espacial de las estelas y determinadas variables geográficas físicas o humanas. Asimismo, se ha utilizado el test de $\chi^{2}$, según la metodología descrita en Shennan (1988: 105 ) con un nivel de confianza de 0,05 , para evaluar si hay alguna relación entre dos variables cualitativas. Finalmente, se ha empleado el test de Shapiro-Wilk que evalúa si existe una distribución normal cuando hay menos de 30 casos, dado que esta prueba es más robusta que la de Kolmogorov-Smirnov.

Respecto a la metodología de análisis empleada en el sistema de información geográfica, se ha creado una capa de fricción a través de un modelo digital del terreno con unos píxeles de unos $20 \mathrm{~m}$ de lado para obtener las áreas isócronas y las rutas óptimas. Para ello, se ha elaborado una superficie de pendientes en términos porcentuales, después dividida entre 10 , a la cual se han sumado los raster de los cursos fluviales de mayor caudal de acuerdo con un valor establecido en 10. Posteriormente, se ha sumado un valor de 1 a todo el raster para evitar que haya celdas con valor 0 , en las cuales el análisis de superficies avanzaría sin coste alguno. 


\begin{tabular}{|c|c|c|c|c|c|c|c|c|}
\hline Nombre & $\begin{array}{c}\text { Zona } \\
\text { geográfica }\end{array}$ & Provincia & $\begin{array}{c}\text { Latitud } \\
\text { (Celestino } \\
\text { Pérez 2001) }\end{array}$ & $\begin{array}{c}\text { Longitud } \\
\text { (Celestino } \\
\text { Pérez 2001) }\end{array}$ & $\begin{array}{l}\text { Coord. } \\
\text { X } \\
\text { (UTM) }\end{array}$ & $\begin{array}{l}\text { Coord. } \\
\text { Y } \\
\text { (UTM) }\end{array}$ & $\begin{array}{c}\text { Reutilización } \\
\text { (según Díaz- } \\
\text { Guardamino } \\
\text { Uribe en } \\
\text { prensa) }\end{array}$ & Bibliografía \\
\hline $\begin{array}{l}\text { Almadén } \\
\text { de la Plata I }\end{array}$ & S. M. & $\mathrm{Se}$ & - & - & 240968 & 4191567 & & $\begin{array}{l}\text { García Sanjuán } \\
\text { et al. } 2006\end{array}$ \\
\hline $\begin{array}{l}\text { Almadén } \\
\text { de la Plata II }\end{array}$ & S. M. & $\mathrm{Se}$ & - & - & 240952 & 4191564 & & $\begin{array}{c}\text { García Sanjuán } \\
\text { et al. } 2006\end{array}$ \\
\hline Belalcázar & S. M. & Co & $38^{\circ} 40^{\prime} 40^{\prime \prime}$ & $1^{\circ} 25^{\prime} 10^{\prime \prime}$ & 316568 & 4282993 & & $\begin{array}{c}\text { Celestino Pérez } \\
\text { 2001: } 403\end{array}$ \\
\hline $\begin{array}{l}\text { Cabeza } \\
\text { de Buey I }\end{array}$ & S. M. & $\mathrm{Ba}$ & $38^{\circ} 48^{\prime} 50^{\prime \prime}$ & $1^{\circ} 33^{\prime}$ & 305580 & 4298369 & & $\begin{array}{c}\text { Celestino Pérez } \\
\text { 2001: } 362\end{array}$ \\
\hline $\begin{array}{l}\text { Cabeza } \\
\text { de Buey II }\end{array}$ & S. M. & $\mathrm{Ba}$ & $38^{\circ} 51^{\prime} 40^{\prime \prime}$ & $5^{\circ} 18^{\prime} 30^{\prime \prime}$ & 299597 & 4303762 & & $\begin{array}{c}\text { Celestino Pérez } \\
\text { 2001: } 364\end{array}$ \\
\hline $\begin{array}{l}\text { Cabeza } \\
\text { de Buey III }\end{array}$ & S. M. & $\mathrm{Ba}$ & $38^{\circ} 42^{\prime} 30^{\prime \prime}$ & $1^{\circ} 38^{\prime} 10^{\prime \prime}$ & 297804 & 4286840 & & $\begin{array}{c}\text { Celestino Pérez } \\
\text { 2001: } 366\end{array}$ \\
\hline $\begin{array}{l}\text { Cancho } \\
\text { Roano }\end{array}$ & S. M. & $\mathrm{Ba}$ & $38^{\circ} 42^{\prime}$ & $5^{\circ} 41^{\prime} 20^{\prime \prime}$ & 266046 & 4286784 & \begin{tabular}{|} 
Reutilizada con \\
fines constructivos \\
en la Edad \\
del Hierro \\
(c. $725-625)$ \\
\end{tabular} & $\begin{array}{c}\text { Celestino Pérez } \\
\text { 2001: } 387\end{array}$ \\
\hline Capilla I & S. M. & $\mathrm{Ba}$ & $38^{\circ} 45^{\prime} 32^{\prime \prime}$ & $1^{\circ} 21^{\prime} 20^{\prime \prime}$ & 322327 & 4291869 & & $\begin{array}{c}\text { Celestino Pérez } \\
\text { 2001: } 371\end{array}$ \\
\hline Capilla II & S. M. & $\mathrm{Ba}$ & $38^{\circ} 45^{\prime} 32^{\prime \prime}$ & $1^{\circ} 21^{\prime} 20^{\prime \prime}$ & 322327 & 4291869 & & $\begin{array}{c}\text { Celestino Pérez } \\
\text { 2001: } 373\end{array}$ \\
\hline Capilla III & S. M. & $\mathrm{Ba}$ & $38^{\circ} 45^{\prime} 32^{\prime \prime}$ & $1^{\circ} 21^{\prime} 20^{\prime \prime}$ & 322327 & 4291869 & & $\begin{array}{c}\text { Celestino Pérez } \\
\text { 2001: } 374\end{array}$ \\
\hline Capilla IV & S. M. & $\mathrm{Ba}$ & $38^{\circ} 43^{\prime} 50^{\prime \prime}$ & $1^{\circ} 22^{\prime} 20^{\prime \prime}$ & 320808 & 4288757 & & $\begin{array}{c}\text { Celestino Pérez } \\
\text { 2001: } 376\end{array}$ \\
\hline Capilla V & S. M. & $\mathrm{Ba}$ & $38^{\circ} 49^{\prime}$ & $1^{\circ} 21^{\prime}$ & 322953 & 4298271 & & $\begin{array}{c}\text { Celestino Pérez } \\
\text { 2001: } 378\end{array}$ \\
\hline Capilla VI & S. M. & $\mathrm{Ba}$ & $38^{\circ} 49^{\prime}$ & $1^{\circ} 21^{\prime}$ & 322953 & 4298271 & & $\begin{array}{c}\text { Celestino Pérez } \\
\text { 2001: } 379\end{array}$ \\
\hline $\begin{array}{l}\text { Castrejón } \\
\text { de Capote }\end{array}$ & S. M. & $\mathrm{Ba}$ & $38^{\circ} 06^{\prime} 20^{\prime \prime}$ & $6^{\circ} 41^{\prime} 10^{\prime \prime}$ & 176658 & 4223813 & $\begin{array}{c}\text { Reutilizada con } \\
\text { fines funerarios } \\
\text { en la Edad } \\
\text { del Hierro } \\
\text { (c. } 725-625)\end{array}$ & $\begin{array}{l}\text { Celestino Pérez } \\
\text { 2001: } 441\end{array}$ \\
\hline Córdoba I & S. M. & $\mathrm{Co}$ & $37^{\circ} 40^{\prime} 10^{\prime \prime}$ & $4^{\circ} 40^{\prime} 20^{\prime \prime}$ & 352405 & 4170320 & & $\begin{array}{c}\text { Celestino Pérez } \\
\text { 2001: } 435\end{array}$ \\
\hline Córdoba II & S. M. & Co & $37^{\circ} 40^{\prime}$ & $4^{\circ} 40^{\prime}$ & 352890 & 4170003 & & $\begin{array}{c}\text { Celestino Pérez } \\
\text { 2001: } 437\end{array}$ \\
\hline El Viso II & S. M. & Co & $38^{\circ} 40^{\prime} 40^{\prime \prime}$ & $1^{\circ} 28^{\prime} 10^{\prime \prime}$ & 312218 & 4283094 & & $\begin{array}{c}\text { Celestino Pérez } \\
\text { 2001: } 396\end{array}$ \\
\hline El Viso III & S. M. & Co & $38^{\circ} 40^{\prime}$ & $1^{\circ} 28^{\prime}$ & 312431 & 4281856 & & $\begin{array}{c}\text { Celestino Pérez } \\
\text { 2001: } 398\end{array}$ \\
\hline El Viso IV & S. M. & Co & $38^{\circ} 42^{\prime} 50^{\prime \prime}$ & $1^{\circ} 21^{\prime} 10^{\prime \prime}$ & 322458 & 4286870 & & $\begin{array}{c}\text { Celestino Pérez } \\
\text { 2001: } 399\end{array}$ \\
\hline El Viso V & S. M. & Co & $38^{\circ} 42^{\prime} 30^{\prime \prime}$ & $1^{\circ} 20^{\prime} 40^{\prime \prime}$ & 323168 & 4286237 & & $\begin{array}{c}\text { Celestino Pérez } \\
\text { 2001: } 401\end{array}$ \\
\hline El Viso VI & S. M. & Co & $38^{\circ} 40^{\prime}$ & $1^{\circ} 28^{\prime}$ & 312431 & 4281856 & & $\begin{array}{c}\text { Celestino Pérez } \\
\text { 2001: } 402 \\
\end{array}$ \\
\hline $\begin{array}{l}\text { Esparragosa } \\
\text { de Lares I }\end{array}$ & S. M. & $\mathrm{Ba}$ & $38^{\circ} 29^{\prime}$ & $5^{\circ} 21$ & 294906 & 4261926 & & $\begin{array}{c}\text { Celestino Pérez } \\
\text { 2001: } 368\end{array}$ \\
\hline $\begin{array}{l}\text { Esparragosa } \\
\text { de Lares II }\end{array}$ & S. M. & $\mathrm{Ba}$ & $38^{\circ} 56^{\prime} 40^{\prime \prime}$ & $5^{\circ} 12^{\prime} 30^{\prime \prime}$ & 308499 & 4312797 & & $\begin{array}{c}\text { Celestino Pérez } \\
\text { 2001: } 369\end{array}$ \\
\hline
\end{tabular}

Trab. Prehist., 70, N. ${ }^{\circ}$ 1, enero-junio 2013, pp 76-94, ISSN: 0082-5638 doi: $10.3989 /$ tp.2013.12103 


\begin{tabular}{|c|c|c|c|c|c|c|c|c|}
\hline Nombre & $\begin{array}{c}\text { Zona } \\
\text { geográfica }\end{array}$ & Provincia & $\begin{array}{c}\text { Latitud } \\
\text { (Celestino } \\
\text { Pérez 2001) }\end{array}$ & $\begin{array}{l}\text { Longitud } \\
\text { (Celestino } \\
\text { Pérez 2001) }\end{array}$ & $\begin{array}{l}\text { Coord. } \\
\text { X } \\
\text { (UTM) }\end{array}$ & $\begin{array}{l}\text { Coord. } \\
\text { Y } \\
\text { (UTM) }\end{array}$ & $\begin{array}{c}\text { Reutilización } \\
\text { (según Díaz- } \\
\text { Guardamino } \\
\text { Uribe en } \\
\text { prensa) }\end{array}$ & Bibliografía \\
\hline $\begin{array}{l}\text { Fuente } \\
\text { de Cantos }\end{array}$ & S. M. & $\mathrm{Ba}$ & $38^{\circ} 13^{\prime} 30^{\prime \prime}$ & $6^{\circ} 18^{\prime} 30^{\prime \prime}$ & 210268 & 4235821 & & $\begin{array}{l}\text { Celestino Pérez } \\
\text { 2001: } 439\end{array}$ \\
\hline $\begin{array}{l}\text { Herrera } \\
\text { del Duque }\end{array}$ & S. M. & $\mathrm{Ba}$ & $38^{\circ} 13^{\prime}$ & $1^{\circ} 18^{\prime} 40^{\prime \prime}$ & 324880 & 4231609 & & $\begin{array}{l}\text { Celestino Pérez } \\
\text { 2001: } 406\end{array}$ \\
\hline Magacela & S. M. & $\mathrm{Ba}$ & $38^{\circ} 45^{\prime} 54^{\prime \prime}$ & $2^{\circ} 02^{\prime} 10^{\prime \prime}$ & 263202 & 4294089 & & $\begin{array}{c}\text { Celestino Pérez } \\
\text { 2001: } 386\end{array}$ \\
\hline $\begin{array}{l}\text { Majada } \\
\text { Honda o } \\
\text { Cabeza } \\
\text { del Buey IV }\end{array}$ & S. M. & $\mathrm{Ba}$ & - & - & 301502 & 4289832 & $\begin{array}{c}\text { Reutilizada con } \\
\text { fines epigráficos } \\
\text { (siglos VIII/ } \\
\text { VII-VI ane) }\end{array}$ & $\begin{array}{l}\text { Domínguez } \\
\text { de la Concha } \\
\text { et al. } 2005\end{array}$ \\
\hline Olivenza & S. M. & $\mathrm{Ba}$ & $38^{\circ} 38^{\prime} 07^{\prime \prime}$ & $7^{\circ} 07^{\prime} 08^{\prime \prime}$ & 141322 & 4284224 & & $\begin{array}{c}\text { Celestino Pérez } \\
\text { 2001: } 409\end{array}$ \\
\hline $\begin{array}{l}\text { Quintana } \\
\text { de la Serena }\end{array}$ & S. M. & $\mathrm{Ba}$ & $38^{\circ} 42^{\prime}$ & $5^{\circ} 41^{\prime}$ & 266529 & 4286770 & & $\begin{array}{c}\text { Celestino Pérez } \\
\text { 2001: } 388\end{array}$ \\
\hline Setefilla & S. M. & $\mathrm{Se}$ & $37^{\circ} 43^{\prime} 40^{\prime \prime}$ & $1^{\circ} 47^{\prime} 30^{\prime \prime}$ & 281359 & 4178371 & $\begin{array}{c}\text { Reutilizada con } \\
\text { fines funerarios } \\
\text { en la Edad } \\
\text { del Hierro } \\
\text { (c. } 725-625)\end{array}$ & $\begin{array}{l}\text { Celestino Pérez } \\
\text { 2001: } 417\end{array}$ \\
\hline $\begin{array}{l}\text { Zarza } \\
\text { Capilla I }\end{array}$ & S. M. & $\mathrm{Ba}$ & $38^{\circ} 48^{\prime}$ & $1^{\circ} 28^{\prime} 30^{\prime \prime}$ & 312053 & 4296671 & & $\begin{array}{c}\text { Celestino Pérez } \\
\text { 2001: } 380\end{array}$ \\
\hline $\begin{array}{l}\text { Zarza } \\
\text { Capilla II } \\
\end{array}$ & S. M. & $\mathrm{Ba}$ & $38^{\circ} 48^{\prime}$ & $1^{\circ} 28^{\prime}$ & 312777 & 4296654 & & $\begin{array}{c}\text { Celestino Pérez } \\
\text { 2001: } 382\end{array}$ \\
\hline $\begin{array}{l}\text { Zarza } \\
\text { Capilla III } \\
\end{array}$ & S. M. & $\mathrm{Ba}$ & $38^{\circ} 48^{\prime}$ & $1^{\circ} 28^{\prime}$ & 312777 & 4296654 & & $\begin{array}{c}\text { Celestino Pérez } \\
\text { 2001: } 383 \\
\end{array}$ \\
\hline Écija I & V. G. & $\mathrm{Se}$ & $37^{\circ} 35^{\prime} 30^{\prime \prime}$ & $4^{\circ} 58^{\prime} 20^{\prime \prime}$ & 325762 & 4162204 & & $\begin{array}{c}\text { Celestino Pérez } \\
\text { 2001: } 422\end{array}$ \\
\hline Écija II & V. G. & $\mathrm{Se}$ & $37^{\circ} 34^{\prime} 30^{\prime \prime}$ & $4^{\circ} 58^{\prime} 20^{\prime \prime}$ & 325723 & 4160354 & & $\begin{array}{c}\text { Celestino Pérez } \\
\text { 2001: } 424\end{array}$ \\
\hline Écija III & V. G. & $\mathrm{Se}$ & $37^{\circ} 29^{\prime}$ & $5^{\circ} 09^{\prime}$ & 309790 & 4150527 & & $\begin{array}{c}\text { Celestino Pérez } \\
\text { 2001: } 425 \\
\end{array}$ \\
\hline Écija IV & V. G. & $\mathrm{Se}$ & $37^{\circ} 34^{\prime} 30^{\prime \prime}$ & $4^{\circ} 58^{\prime} 20^{\prime \prime}$ & 325832 & 4160558 & & $\begin{array}{c}\text { Celestino Pérez } \\
\text { 2001: } 427\end{array}$ \\
\hline Écija V & V. G. & $\mathrm{Se}$ & - & - & 325600 & 4147967 & & $\begin{array}{c}\text { Padilla Monge } \\
\text { y Valderrama } \\
\text { Juan, } 1994 \\
\end{array}$ \\
\hline Ategua & V. G. & Co & $37^{\circ} 44^{\prime} 10^{\prime \prime}$ & $4^{\circ} 40^{\prime} 40^{\prime \prime}$ & 352048 & 4177726 & & $\begin{array}{c}\text { Celestino Pérez } \\
\text { 2001: } 430\end{array}$ \\
\hline Burguillos & V. G. & $\mathrm{Se}$ & $37^{\circ} 34^{\prime} 50^{\prime \prime}$ & $5^{\circ} 57^{\prime} 30^{\prime \prime}$ & 238644 & 4163258 & & $\begin{array}{c}\text { Celestino Pérez } \\
\text { 2001: } 419\end{array}$ \\
\hline Carmona & V. G. & $\mathrm{Se}$ & $37^{\circ} 26^{\prime}$ & $5^{\circ} 29^{\prime}$ & 280166 & 4145704 & & $\begin{array}{l}\text { Celestino Pérez } \\
\text { 2001: } 415\end{array}$ \\
\hline Los Palacios & V. G. & $\mathrm{Se}$ & $37^{\circ} 10^{\prime}$ & $5^{\circ} 56^{\prime}$ & 239423 & 4117255 & & $\begin{array}{l}\text { Celestino Pérez } \\
\text { 2001: } 420\end{array}$ \\
\hline Montemolín & V. G. & $\mathrm{Se}$ & $37^{\circ} 17^{\prime} 40^{\prime \prime}$ & $5^{\circ} 21^{\prime} 20^{\prime \prime}$ & 291089 & 4130002 & & $\begin{array}{l}\text { Celestino Pérez } \\
\text { 2001: } 429\end{array}$ \\
\hline Pedro Abad & V. G. & Co & $37^{\circ} 50^{\prime}$ & $4^{\circ} 40^{\prime} 10^{\prime \prime}$ & 352975 & 4188501 & & $\begin{array}{l}\text { Celestino Pérez } \\
\text { 2001: } 433\end{array}$ \\
\hline
\end{tabular}

Tab. 1. Relación de estelas incluidas en el estudio. S. M. (Sierra Morena) V. G (Valle del Guadalquivir). Ba (Badajoz) Co (Córdoba) Se (Sevilla). 


\section{ANÁLISIS ESPACIAL DE LA DISTRIBUCIÓN DE LAS ESTELAS}

Se estudian aquí 44 estelas, procedentes de las provincias de Badajoz $(22=50 \%)$, Córdoba $(10=$ $23 \%)$ y Sevilla $(12=27 \%)$. En Sierra Morena se han encontrado $33(75 \%)$ y 11 en el valle del Guadalquivir (25\%). Como se ha indicado anteriormente, se ha empleado la zona geográfica de hallazgo para clasificar las estelas y efectuar los análisis espaciales, obviando las diferencias existentes en los motivos representados. Primero se ha evaluado la distribución de las estelas en función de variables geográficas como altitud, calidad de los suelos, distancia a los ríos, etc. y, después, considerando variables relacionadas con la ocupación del territorio durante la Edad del Bronce Final como, por ejemplo, los asentamientos o las rutas óptimas entre ellos.

¿Existe alguna relación entre las estelas y la altitud de su área de hallazgo? En la figura 4 se puede comprobar que tienen una distribución normal de acuerdo con esta variable y que la mayoría se ubican entre los 200 y $500 \mathrm{~m}$ de altitud. Para evaluar estadísticamente si se distribuyen de manera normal se ha aplicado el test de ShapiroWilk al número total de estelas seleccionadas. El resultado obtenido $(0,93)$, menor que el valor crítico $(0,98)$, indica que no hay una relación estadística entre su distribución y la altura. La altitud media del total de estelas seleccionadas es de 338 $\mathrm{m}$, frente a los $168 \mathrm{~m}$ de las halladas en el valle del Guadalquivir y a los $390 \mathrm{~m}$ de las de Sierra Morena. Este hecho está claramente relacionado con las diferentes condiciones orogénicas de cada área. Al comparar la distribución de ambos grupos de acuerdo con esta variable por medio de la prueba de Kolmogorov-Smirnov, se observa que la máxima diferencia encontrada $(0,428)$ es menor que el valor crítico $(0,474)$, lo que demostraría que ambas distribuciones son iguales. Es decir, la distribución espacial de estos monumentos podría no haber estado relacionada con esta variable, aunque algunos investigadores han señalado que las estelas estarían localizadas en lugares de baja altitud (Celestino Pérez 2001: 76).

Para contrastar la hipótesis de que las estelas se distribuyen según la pendiente de la zona de hallazgo se ha calculado esta variable porcentualmente, clasificando los monumentos de acuerdo con esta información (Fig. 4). La mayoría se ubi-
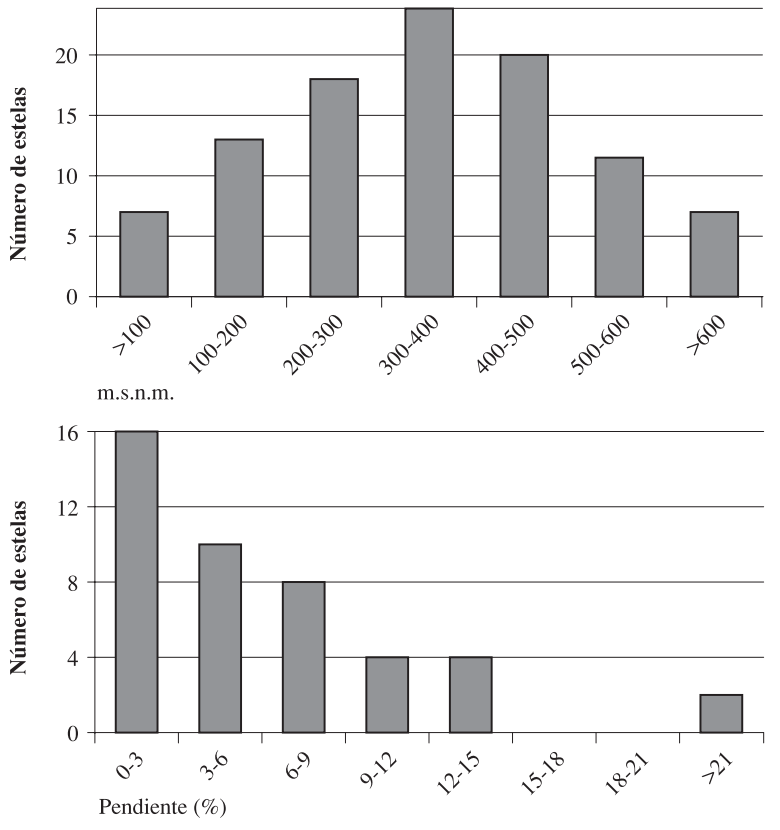

Fig. 4. Distribución de las 44 estelas estudiadas en Sierra Morena y el valle del Guadalquivir de acuerdo con: 1. la altitud de las coordenadas de localización; 2. su pendiente. Se identifican en la tabla 1.

can en áreas con menos de un 6\% de pendiente, es decir, accesibles siempre y cuando no hubiera existido una vegetación densa. Tras aplicar el test de Kolmogorov-Smirnov, para comprobar si podría existir alguna relación entre su distribución y esta variable, se ha observado que la diferencia máxima entre la distribución esperada y observada $(0,08)$ es inferior al valor crítico para 44 grados de libertad $(0,20)$. Este dato parece indicar que la pendiente podría no haber influido en su distribución, aunque hay que tener en cuenta que el error estimado de $100 \mathrm{~m}$ de las coordenadas geográficas empleadas en este estudio es un efecto distorsionador a tener en cuenta. Dado que las condiciones orogénicas varían en las dos zonas seleccionadas, se ha calculado la pendiente media de las estelas de cada una. En Sierra Morena tienen una pendiente media $(6,17 \%)$ ligeramente superior a la de las estelas del valle del Guadalquivir (4,72\%). Al comparar ambas distribuciones por medio del test de Kolmogorov-Smirnov, se demuestra que el valor máximo $(0,06)$ es inferior al valor crítico $(0,474)$, hecho que confirma que la distribución de estelas de acuerdo con esta variable parece similar en ambas zonas. 
Posteriormente, se ha evaluado la relación entre dicha distribución y la calidad de los suelos en los que se ubican, variable que algunos investigadores han descartado para explicar su ubicación espacial (Galán Domingo 1993: 36). Actualmente, las clasificaciones del suelo más conocidas son la $U S D A$ y la elaborada por la $F A O$. Aún de gran utilidad desde el punto de vista de la agricultura moderna, no pueden ser empleadas para el estudio del pasado, ya que su productividad se ha estimado en base a la tecnología actualmente disponible. Para solventar este problema, el mapa de suelos ha sido reclasificado en tres categorías básicas basadas en su fertilidad y calidad: suelos muy productivos (entisoles y vertisoles), productivos (alfisoles) y no productivos (inceptisoles y ultisoles), que solo podrían haber sido empleados para pasto. Una clasificación similar ha dado resultados satisfactorios en otros estudios espaciales (García Sanjuán y Hurtado Pérez 1998; Nocete Calvo 1994). Tras ordenar estos monumentos según estas categorías (Tab. 2), se ha observado que la mayoría de las estelas se localizan en suelos muy pobres.

Para contrastar esta hipótesis se ha empleado la prueba de $\chi^{2}$, cuyo resultado $(0,96)$ es menor que el valor crítico para 2 grados de libertad $(5,99)$. Esto indica que la calidad del suelo podría no haber sido determinante en la distribución espacial de las estelas y demuestra que la hipótesis de Galán Domingo sería estadísticamente consistente. Sin embargo, un análisis global que minusvalorara las diferencias existentes entre áreas geográficas podría tener un efecto distorsionador importante. Por ello los monumentos de cada zona seleccio- nada se han clasificado de nuevo para valorar si su distribución es diferente de acuerdo con esta variable. Si se aplica el test de $\chi^{2}$ se advierte que el resultado obtenido $(7,16)$ es superior al del valor crítico $(5,99)$, lo que significa que la distribución de las estelas de cada área difiere. Hasta el momento en las pruebas estadísticas se han comparado las coordenadas geográficas de ubicación de cada estela, pero no el área cercana a estos monumentos. Como estas coordenadas podrían tener desviaciones de $100 \mathrm{~m}$ para minimizar el posible error se han calculado las áreas isócronas a una hora de distancia respecto de cada estela y el suelo ubicado dentro de las áreas se ha clasificado de acuerdo con su calidad según el esquema anterior (Tab. 2). Al comparar los valores para Sierra Morena y para el valle del Guadalquivir por medio de la prueba de $\chi^{2}$ se obtiene un resultado $(174,45)$ superior al valor crítico para dos grados de libertad $(5,99)$. Esto quiere decir que hay una diferencia significativa entre los suelos cercanos a las estelas de ambas áreas. Por lo tanto, puede que si las estelas hubieran tenido una posible relación territorial respecto a esta variable esta hubiese diferido entre las dos zonas geográficas seleccionadas.

A pesar de las diferencias anteriores, muchas estelas de ambas zonas están próximas a áreas de contacto entre suelos de distinta calidad y con potenciales agropecuarios distintos (Fig. 5). El cálculo de la distancia a este límite según el mapa de suelos a escala 1:400.000 demuestra que estos monumentos están a una distancia media de $3,66 \mathrm{~km}$ y a una mediana de 1,68 km del límite más cercano. En el análisis de su distribución en

\begin{tabular}{|l|c|c|c|c|c|c|}
\hline \multirow{2}{*}{ Tipos de suelo } & \multicolumn{3}{|c|}{ Número de estelas } & \multicolumn{2}{c|}{$\begin{array}{c}\text { Superficie dentro de las áreas isócronas } \\
\text { a una hora de distancia (km²) }\end{array}$} \\
\cline { 2 - 7 } & Total & $\begin{array}{c}\text { Valle del } \\
\text { Guadalquivir }\end{array}$ & $\begin{array}{c}\text { Sierra } \\
\text { Morena }\end{array}$ & Total & $\begin{array}{c}\text { Valle del } \\
\text { Guadalquivir }\end{array}$ & Sierra Morena \\
\hline Muy productivo & $7(16 \%)$ & $4(37 \%)$ & $3(10 \%)$ & $\begin{array}{c}316,15 \\
(30 \%)\end{array}$ & $138,95(22 \%)$ & $177,20(43 \%)$ \\
\hline Productivo & $7(16 \%)$ & $3(36 \%)$ & $3(10 \%)$ & $\begin{array}{c}235,91 \\
(23 \%)\end{array}$ & $91,37(15 \%)$ & $144,54(35 \%)$ \\
\hline No productivo & $30(68 \%)$ & $4(27 \%)$ & $24(80 \%)$ & $\begin{array}{c}488,77 \\
(47 \%)\end{array}$ & $399,61(63 \%)$ & $89,16(22 \%)$ \\
\hline
\end{tabular}

Tab. 2. Distribución de las estelas según la calidad del suelo del área de hallazgo. 


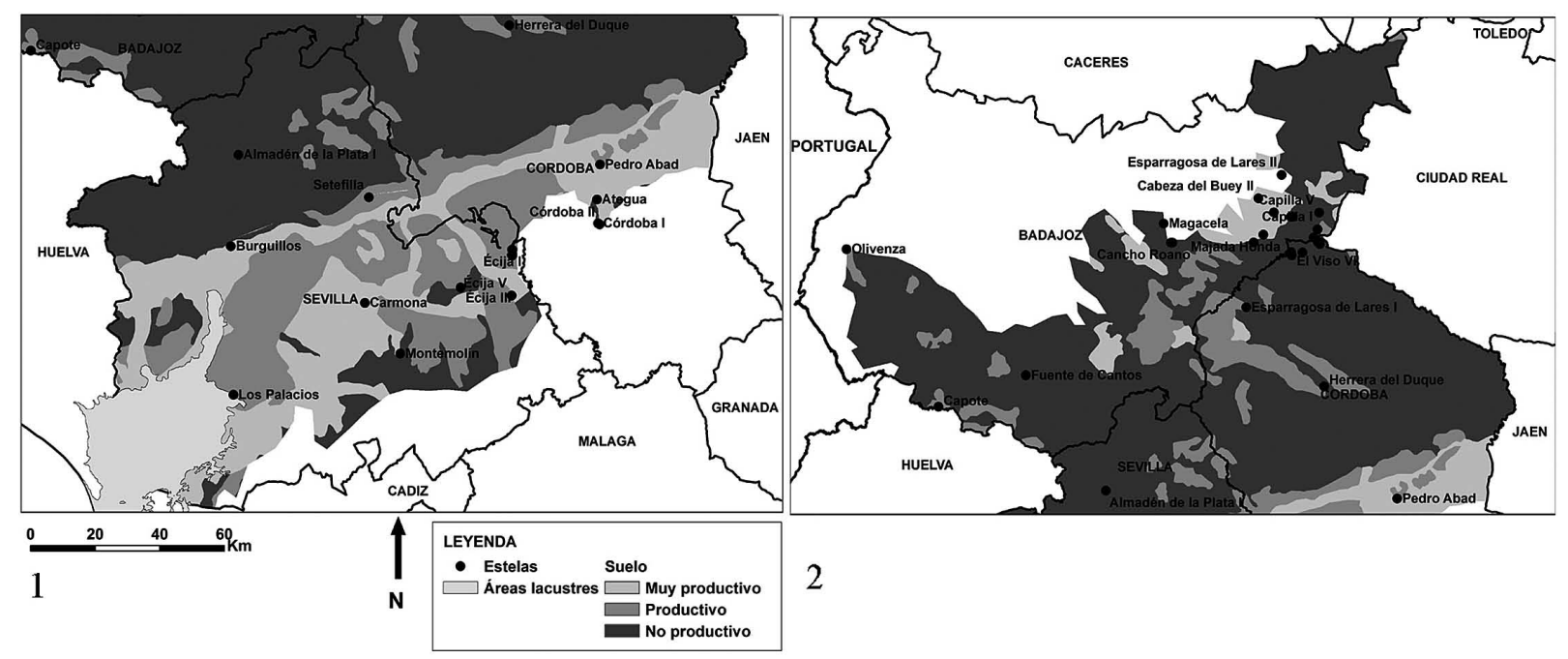

Fig. 5. Distribución de las 44 estelas estudiadas en el valle del Guadalquivir (1) y Sierra Morena (2) de acuerdo con la calidad agrícola del suelo.

un diagrama de frecuencia (Fig. 6) se observa que la mayoría de las estelas distan menos de $2 \mathrm{~km}$ de dichos límites, aunque otro grupo supera los $6 \mathrm{~km}$. Esto podría deberse a la reutilización y a la remoción posterior de algunas estelas (DíazGuardamino Uribe 2012). Otras alternativas son que la escala del mapa de suelos empleada impidiera identificar las pequeñas variaciones locales y que la reclasificación del mapa del suelo en 3 clases básicas hubiera matizado diferencias existentes en determinadas zonas. Las estelas del valle del Guadalquivir y de Sierra Morena distan una media de $0,885 \mathrm{~km}$ y $3,64 \mathrm{~km}$ respectivamente del límite entre suelos de diferente calidad. Esto podría indicar diferencias en la elección del lugar de emplazamiento de dichos monumentos en ambas zonas. Tampoco debería descartarse la influencia de las simbologías y creencias de cada comunidad en los motivos representados y en la localización de las estelas.

¿Existe alguna relación entre la distribución espacial de las estelas y la distancia a los principales ríos? La figura 6 muestra como la mayor parte de estos monumentos distan menos de $1 \mathrm{~km}$ del río más cercano. Las estelas de Zarza Capilla y Cabeza de Buey, ubicadas en el sur de Badajoz, están a 6-7 km debido a que en esta zona hay arroyos, como por ejemplo el Tamujoso o el de Dos Hermanas, pero no ríos de gran entidad. Se ha aplicado el análisis de Kolmogorov-Smirnov para comprobar si existe una relación estadísticamente consistente entre las localizaciones de las estelas y los ríos de mayor entidad. Se ha obtenido un resultado de 0,29 , frente al valor crítico de 0,20 para 44 grados de libertad, por lo que la hipótesis nula debería ser rechazada. Esto significa que las estelas pudieron distribuirse siguiendo los ríos, que en muchos casos son la mejor ruta de comunicación en áreas de orografía compleja, por lo que podrían haber sido empleados como rutas de intercambio y ganaderas. A su vez, podría ser una evidencia de que las estelas se ubicaron como delimitadores territoriales en zonas de paso (Galán Domingo 1993: 28-30).

Si la pauta anterior fuera cierta sería conveniente plantearse si pudo haber alguna relación espacial entre su distribución y los asentamientos de la Edad del Bronce Final, asumiendo que estructuraron el territorio de su entorno. Galán Domingo (1993: 60) ha defendido que no hubo tal relación aunque hasta el momento los estudios que han contrastado esta posibilidad por medio de un sistema de información geográfico son escasos, a excepción del trabajo ya referido (Celestino Pérez et al. 2012). Con este objetivo se ha calculado la distancia lineal a los asentamientos más cercanos y se ha creado el correspondiente histograma (Fig. 6). Se observa cómo las estelas no tienen una distribución normal de acuerdo con esta medida, posiblemente porque existen varios 

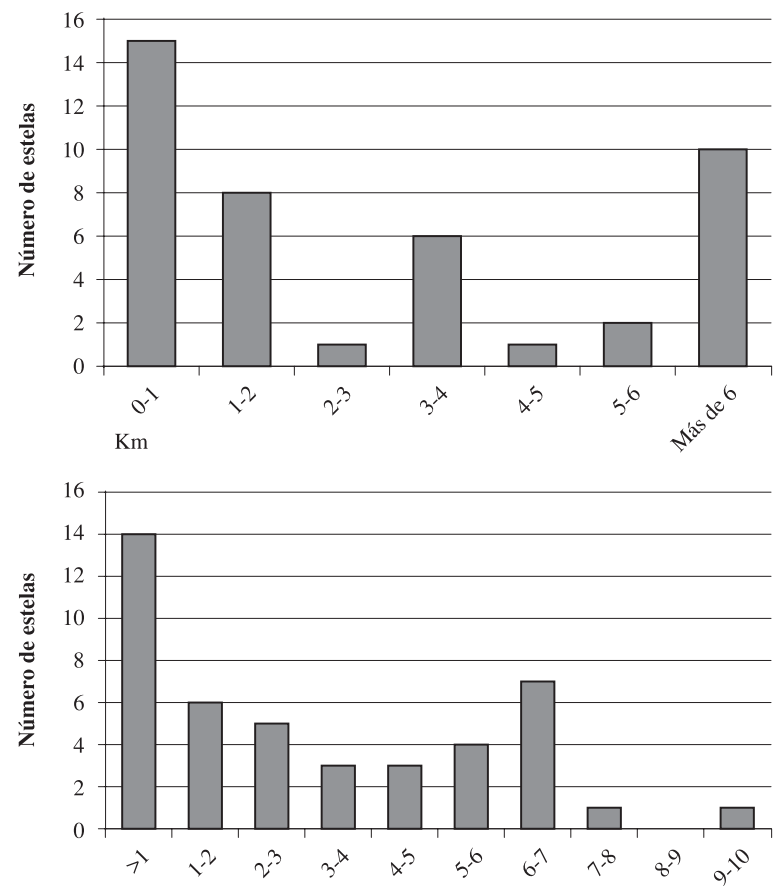

$\mathrm{Km}$

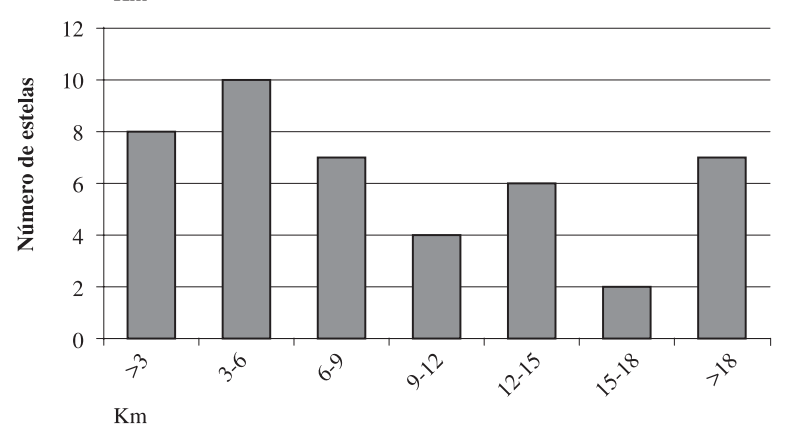

Fig. 6. Distribución de las 44 estelas estudiadas en el valle del Guadalquivir y Sierra Morena de acuerdo con su distancia lineal: 1. a las zonas de contacto entre suelos de diferente calidad; 2. a los ríos principales; 3. a los poblados más cercanos de ese periodo.

grupos de acuerdo con esta variable y debido a que la investigación es heterogénea en todo el área seleccionada. Por ejemplo, en Sierra Morena se conocen pocos poblados a diferencia del valle del Guadalquivir, que ha sido objeto de numerosos trabajos de prospección y excavación desde finales del siglo XIX e inicios del siglo XX (Fig. 7). Al calcular la distancia media de todas las estelas seleccionadas respecto de los poblados más cercanos $(10,9 \mathrm{~km})$, así como las de las halladas en Sierra Morena (12,9 km) y el valle del Guadal- quivir (4,8 km), se demuestra que en los tres casos la mayoría no se ubicaron en las inmediaciones de los asentamientos.

La lejanía entre estelas y poblados ha sido interpretada como una evidencia clara de que estas podrían haberse emplazado en los límites entre territorios de diferentes comunidades sin asentamientos permanentes (Galán Domingo 1993: 60), aunque por el momento esta hipótesis es incontrastable. Para evaluar la relación entre la distribución de las estelas y la ubicación de los asentamientos del Bronce Final, algunos de los cuales siguieron ocupados en la Primera Edad del Hierro, se ha aplicado la prueba de Kolmogorov-Smirnov solo a los monumentos del valle del Guadalquivir, dado los pocos poblados conocidos del Bronce Final en Sierra Morena. Esta prueba obtiene una diferencia máxima $(0,33)$ entre la distribución observada y la esperada, que es inferior al valor crítico para 0,05 grados de confianza $(0,39)$. Por lo tanto, parece que la distribución de las estelas podría no haber estado relacionada con la localización de los asentamientos, aunque recordemos que la heterogeneidad de la información arqueológica disponible podría haber actuado como un elemento distorsionador.

Los resultados anteriores se han comparado calculando las áreas isócronas a una hora de distancia de las estelas situadas en el valle del Guadalquivir con el objetivo de evaluar su cercanía a los asentamientos en términos de coste expresado en unidades de tiempo. El análisis se ha centrado en la zona entre los ríos Corbones y Genil, intensamente prospectada y donde se conocen un gran número de asentamientos de la Edad del Bronce Final y de la Primera Edad del Hierro (Durán Recio 1990; Ferrer Albelda et al. 2001; Ferrer Albelda 2007; Domínguez Berenjeno y Cerveza Pozo 2009). Se observa (Fig. 8) que las estelas de Montemolín, Écija III, V y Carmona distan menos de una hora de distancia a pie de uno o dos poblados. Esto sugiere que, efectivamente, la aparente falta de relación espacial entre estos monumentos y los asentamientos podría estar muy influida por la investigación llevada a cabo y sobre todo por el número de asentamientos identificados en las prospecciones arqueológicas. En este contexto, parece demostrarse que mientras no aumente la información disponible sobre los poblados será muy difícil evaluar la posible funcionalidad territorial de las estelas. 

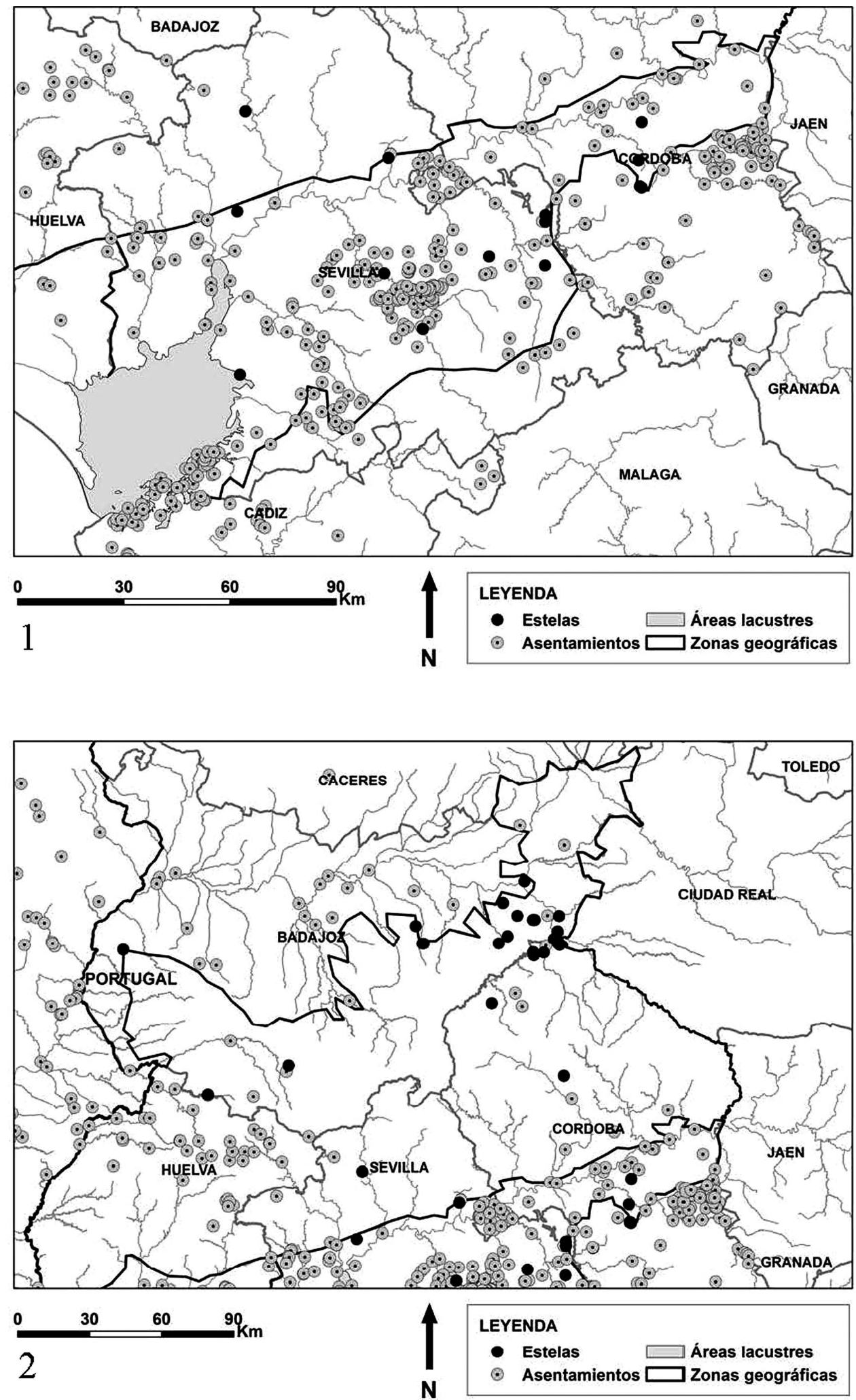

Fig. 7. Estelas y asentamientos de la Edad del Bronce Final: 1. en el valle del Guadalquivir; 2. en Sierra Morena.

Trab. Prehist., 70, N. ${ }^{o}$ 1, enero-junio 2013, pp 76-94, ISSN: 0082-5638

doi: $10.3989 /$ tp. 2013.12103 


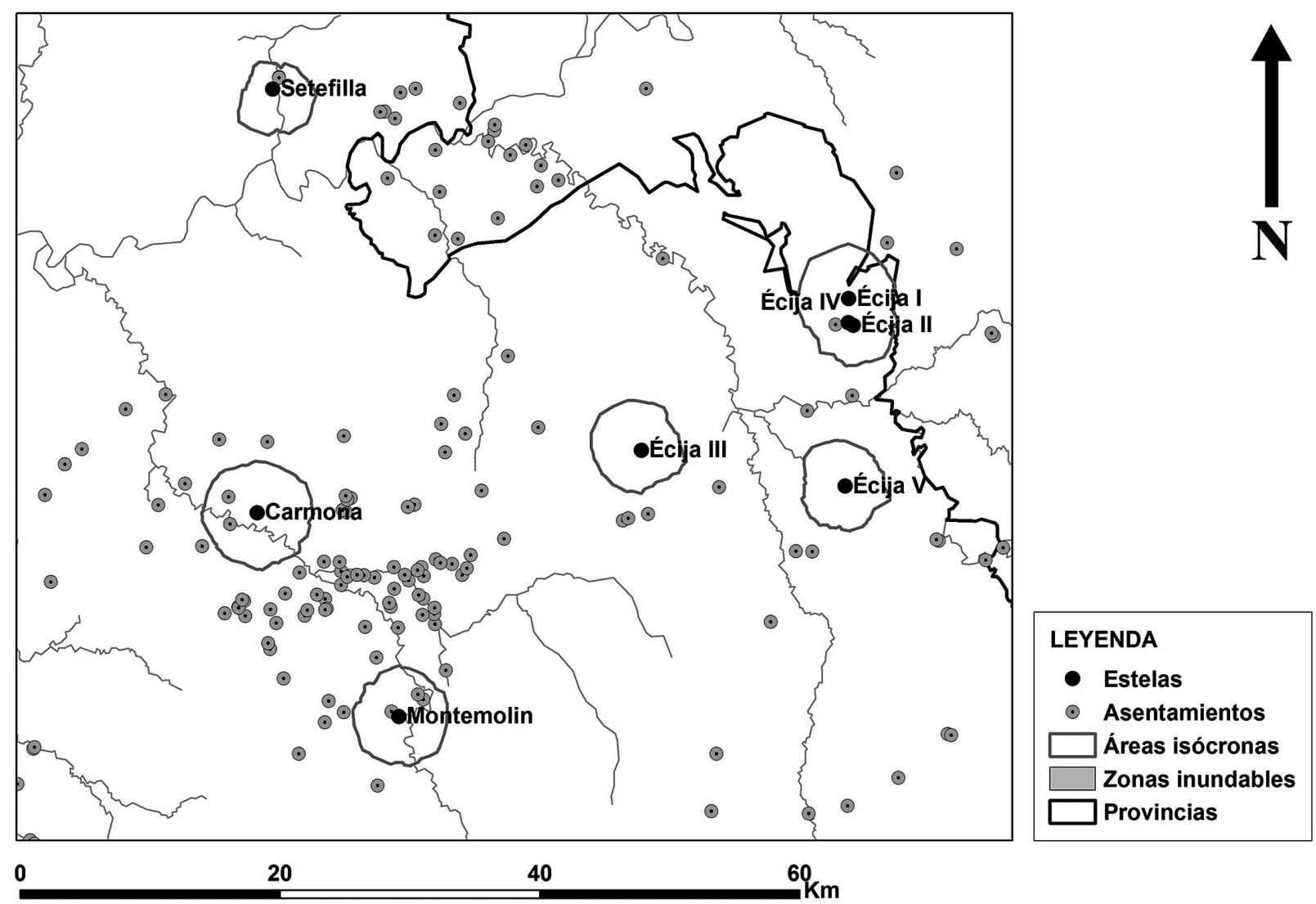

Fig. 8. Áreas isócronas de una hora de distancia con centro en las estelas y asentamientos de la Edad del Bronce Final en los valles de los ríos Corbones, Genil y Guadalquivir.

Con el objetivo de complementar los resultados anteriores, se ha evaluado la posible relación entre las rutas óptimas y la distribución de las estelas. Esta se ha calculado a partir de los principales asentamientos del Bronce Final, que podrían haber perdurado en la Edad del Hierro. Un análisis similar ha documentado la posición de una alta proporción de estelas en rutas óptimas y zonas de paso, a excepción de dos que podrían haber sido reutilizadas en construcciones posteriores (Celestino Perez et al. 2012: 144). Este análisis se ha aplicado solo al valle del río Corbones, intensamente prospectado. Se ha excluido Sierra Morena, dada la escasez de asentamientos documentados y a pesar de que su orografía compleja es ideal para efectuar análisis de este tipo, y el valle del Genil, sin prospecciones intensivas, ni estudios territoriales para la Edad del Bronce Final. Al desconocerse las dimensiones de los asentamientos es imposible identificar posibles rangos en base a su tamaño, lo que dificulta el cálculo de las rutas óptimas entre los más importantes. En el valle del río Corbones se han escogido como asentamientos principales Carmona, Montemolín-Vico, La Torre, La Fábrica y Porcún, los de mayores dimensiones según el estudio territorial publicado para esta zona (García Fernández 2003). Posteriormente, se han calculado las rutas óptimas entre el resto de asentamientos y estos poblados y se ha evaluado la ubicación de las estelas en relación con las mismas (Fig. 9). Se observa que las estelas están próximas a dichas rutas, ya que por ejemplo la de Carmona dista menos de $200 \mathrm{~m}$, la de Montemolín a $500 \mathrm{~m}$ y la de Écija III a $120 \mathrm{~m}$, sin que se deba obviar que las coordenadas de las estelas podrían estar desplazadas unos $100 \mathrm{~m}$ por su remoción en las labores agrícolas. En definitiva, parece que podría 


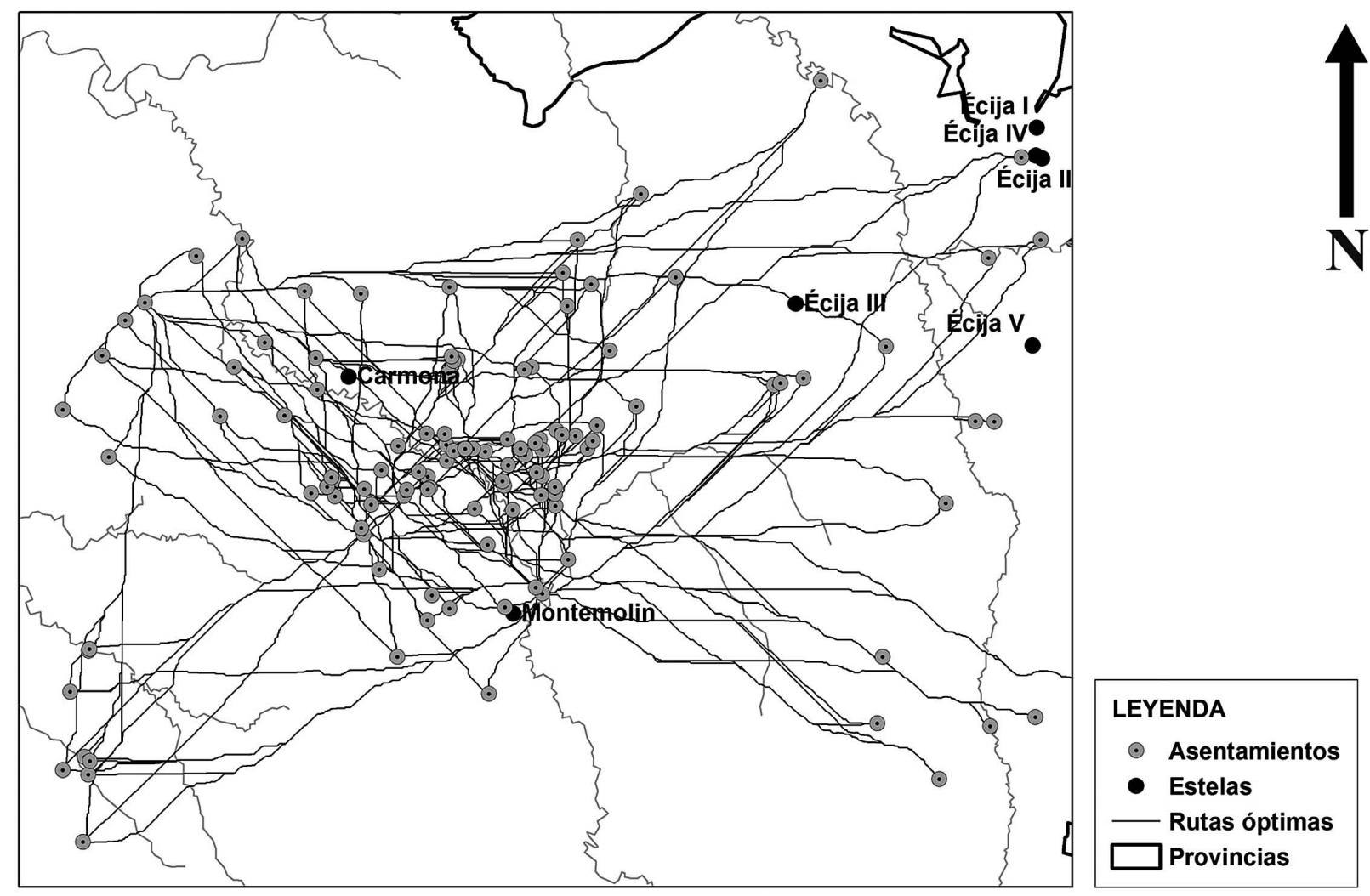

Fig. 9. Ubicación de las estelas en la vega del río Corbones (valle del Guadalquivir) respecto a las rutas óptimas entre asentamientos de la Edad del Bronce Final.

haber existido una relación entre estas rutas y la ubicación de las estelas, como ya se ha defendido (Celestino Pérez et al. 2012). No obstante no se ha podido evaluar esta pauta mediante el test de Kolmogorov-Smirnov ya que los 3 monumentos documentados en la zona de estudio no bastan para aplicar esta prueba estadística.

Finalmente, se ha evaluado si la visibilidad pudo ser un factor importante en la distribución de las estelas. Esta variable, obviada por los estudios espaciales de la Nueva Arqueología (Wheatley y Gillings 2002: 180), ha sido empleada frecuentemente en los trabajos de investigación postprocesuales como un elemento importante en la construcción cultural del paisaje. Teóricamente si la función de las estelas hubiera estado relacionada con el paisaje tendrían que haber estado situadas en áreas de gran visibilidad. Sin embargo, su altura media es de $140-150 \mathrm{~cm}$ y sus grabados solo son visibles a varios metros de distancia, ar- gumentos empleados para poner en cuestión su relación con esta variable (Harrison 2004: 34). Tampoco ha evaluado este aspecto a día de hoy ningún estudio espacial con una metodología formalizada de análisis. Para solventarlo se ha calculado la visibilidad dentro de buffers de $1 \mathrm{~km}$ en torno a las estelas, sumando posteriormente la superficie visible. La mayoría de la superficie cercana a las estelas es visible, pero un alto porcentaje de la misma no lo es desde la coordenada

\begin{tabular}{|l|c|c|c|}
\hline & $\begin{array}{c}\text { Area total } \\
\left(\mathbf{k m}^{2}\right)\end{array}$ & $\begin{array}{c}\text { Sierra } \\
\text { Morena (\%) }\end{array}$ & $\begin{array}{c}\text { Valle del } \\
\text { Guadalquivir (\%) }\end{array}$ \\
\hline Visible & $\begin{array}{l}130,61 \\
(69 \%)\end{array}$ & $\begin{array}{c}95,96(67 \\
\%)\end{array}$ & $34,65(71 \%)$ \\
\hline $\begin{array}{l}\text { No } \\
\text { visible }\end{array}$ & $\begin{array}{l}281,44 \\
(31 \%)\end{array}$ & $\begin{array}{c}198,35 \\
(33 \%)\end{array}$ & $83,09(29 \%)$ \\
\hline
\end{tabular}

Tab. 3. Visibilidad del entorno cercano a las estelas seleccionadas desde $1 \mathrm{~km}$ de distancia. 
geográfica en la que se sitúa el monumento (Tab. $3)$. Si se comparan estos resultados con el área geográfica de procedencia se demuestra que los valores son muy similares a pesar de las diferentes condiciones orográficas de cada una de ellas. La prueba de $\chi^{2}$ da un resultado $(0,39)$ inferior al valor crítico para un grado de libertad $(3,84)$. Según estos datos, la hipótesis nula no podría ser rechazada por lo que no se documenta ninguna diferencia entre la superficie visible de las estelas de cada zona. No obstante, es importante señalar que los resultados obtenidos están fuertemente distorsionados por la imprecisión de las coordenadas geográficas. Un pequeño error de algunos metros de elevación podría incrementar o reducir la visibilidad del emplazamiento de manera significativa, argumento que ha sido empleado para rechazar este tipo de estudios dada la variabilidad de los resultados (Celestino Pérez 2012: 142). Asimismo, advertimos que, en este estudio, no se ha considerado la vegetación, un factor que podría haber reducido la visibilidad notablemente.

\section{CONCLUSIONES}

A día de hoy existe un debate intenso sobre la funcionalidad de las estelas del Suroeste de la Península Ibérica que, lejos de estar resuelto, ha ido adquiriendo una mayor intensidad gracias a la publicación de nuevos estudios. La mayoría de los investigadores que han considerado las estelas como monumentos funerarios han fundamentado su hipótesis en el análisis morfológico de los grabados y en su composición figurativa (Almagro Basch 1966; Celestino Pérez 2001; Harrison 2004). Asimismo se han identificado diferentes concentraciones a partir de las coordenadas del área de hallazgo y la composición figurativa de las estelas (Celestino Pérez 2001; Celestino Pérez et al. 2011), que algunos investigadores han relacionado con motivos ideológicos o funcionales (García Sanjuán 2010: 3). A pesar de estas hipótesis, desde mediados de los años 90 del siglo XX se ha producido un aumento de publicaciones que han puesto énfasis en la función territorial de estos monumentos como hitos o delimitadores territoriales (Galán Domingo 1993; García Sanjuán et al. 2006), aunque hasta el momento son escasos los estudios que han aplicado análisis espaciales a su distribución por medio de sistemas de información geográfica y de acuerdo con una metodología formalizada de análisis (Celestino Pérez et al. 2012).

Los resultados obtenidos en el estudio espacial llevado a cabo solo deberían ser considerados para las áreas geográficas analizadas, sin que sean extrapolables a otras con altas concentraciones de estelas y en donde podrían documentarse pautas diferentes relacionadas o no con las variables analizadas en este trabajo de investigación. Tampoco se ha tenido en cuenta la información iconográfica de las propias estelas seleccionadas, ni su posible relación con las variables analizadas, ámbito de estudio que dada su complejidad necesitaría de un estudio monográfico específico que excede los objetivos de este artículo. Otro aspecto que no debería ser minusvalorado es la cronología de las estelas y su posible reutilización en períodos posteriores (Díaz-Guardamino Uribe 2010, 2012; Celestino Pérez et al. 2012), que podrían haber influido y distorsionado su distribución espacial. En resumen podría decirse que los resultados obtenidos tienen un claro valor orientativo sin que, en ningún caso, dada la incertidumbre sobre la procedencia exacta de dichos monumentos, deban ser considerados como definitivos.

Según las pruebas estadísticas empleadas, determinadas variables geográficas evaluadas como la visibilidad, la pendiente o la altitud podrían no haber estado relacionadas con la distribución espacial de las estelas, en contra de lo que hasta el momento se pensaba (véase Celestino Pérez 2001: 76 respecto a la altitud). De hecho, en muchos casos no existen diferencias estadísticamente significativas al comparar estas variables en los monumentos de las dos zonas geográficas seleccionadas. En este contexto sería interesante reflexionar en qué medida se podría matizar su importancia en futuros estudios espaciales. Sin embargo, sería conveniente volver a analizar estas variables si los análisis se aplicasen a otras zonas de estudio o con otras escalas de análisis $\mathrm{o}$, si se produjera un aumento significativo del número de estelas conocidas en las zonas seleccionadas o una mejora sustancial en la calidad de la información georreferenciada. Como ya han señalado otros investigadores, a día de hoy falta una evaluación de la calidad de las coordenadas de las estelas que mejore la precisión de los análisis espaciales efectuados (Celestino Perez et al. 2012: 149).

Trab. Prehist., 70, N. ${ }^{\circ}$ 1, enero-junio 2013, pp 76-94, ISSN: 0082-5638 doi: $10.3989 /$ tp.2013.12103 
El análisis de la relación entre estelas y calidad del suelo a escala global parece probar que esta variable podría no haber influido en su distribución, como algunos investigadores han defendido (Galán Domingo 1993: 36). Sin embargo, se ha demostrado que las estelas de las dos zonas seleccionadas se emplazan sobre suelos de diferente calidad. Ello sugiere que el análisis a escala global podría haber distorsionado los resultados obtenidos al minusvalorar las diferencias geográficas existentes entre ambas, ya que de hecho en el valle del Guadalquivir estos monumentos se ubican en suelos de buena calidad y en Sierra Morena en zonas idóneas para pasto. Por el contrario, cuando se calculan las áreas isócronas a una hora de distancia y se observa la composición porcentual de la superficie incluida en las mismas en relación con la calidad del suelo se documenta la tendencia inversa: las estelas del valle del Guadalquivir tienen en sus cercanías un alto porcentaje de has aptas para pasto pero no para la agricultura y las de Sierra Morena de superficie idónea para usos agrícolas. Más allá de estas diferencias, destacamos que en ambas zonas las estelas están localizadas en áreas de contacto entre suelos con diferente calidad. Esto tendría importantes repercusiones al interpretar su posible funcionalidad territorial, ya que su significación como posibles hitos territoriales podría haber variado de acuerdo con las diferentes condiciones geográficas de cada zona. En este sentido, sería aconsejable que en el futuro el análisis espacial de las estelas se efectuase de manera individualizada por zonas, evitando la escala geográfica global de estudio que se ha empleado en la mayoría de los trabajos publicados hasta ahora.

Gran parte de las estelas seleccionadas están a una distancia lineal superior a los $3 \mathrm{~km}$ de los asentamientos del Bronce Final más próximos. Algunos investigadores han considerado esta lejanía como una prueba evidente de la desconexión entre la distribución de estos monumentos y los asentamientos (Galán Domingo 1993: 60). Sin embargo, la investigación llevada a cabo en el Suroeste podría haber distorsionado el estudio espacial efectuado en las dos zonas seleccionadas que cuentan con una información arqueológica variable. En el valle del Guadalquivir se conocen una gran cantidad de asentamientos del Bronce Final y pocas estelas, mientras que en Sierra Morena son muy pocos por la escasez de prospecciones efectuadas, pero hay gran cantidad de estelas. A su vez, habría que plantearse que para mejorar el estudio de esta variable es imprescindible una mejora correlativa de la información sobre los asentamientos de este período.

Según este estudio, la distribución de las estelas podría haber estado relacionada con la localización de los principales ríos, en cuyas cercanías podrían haber existido rutas de comunicación idóneas sobre todo en áreas de orografía compleja. El análisis de las rutas óptimas, como el de la vega del río Corbones, ha sido bastante ilustrativo en este sentido. No obstante no se ha podido aplicar a otras áreas del Suroeste peninsular prospectadas pero sin estelas o en donde se documenta la situación inversa. Tras el cálculo de las áreas isócronas en los valles de los ríos Corbones y Genil se observa que muchas de las estelas se encuentran a menos de una hora de camino a pie al menos de un asentamiento conocido con evidencias de ocupación del Bronce Final y que en muchos casos se localizan cerca de las rutas óptimas entre asentamientos. Una situación similar se constata en la Sierra de Montánchez, donde algunos monumentos podrían haber estado en relación con las rutas óptimas de comunicación, mientras otros no lo estaban, posiblemente por su reutilización y remoción de su lugar original (Celestino Pérez et al. 2012: 144). En resumen, se podría decir que las estelas de la vega del Corbones podrían haberse emplazado en las cercanías de las rutas óptimas entre poblados y en zonas de contacto entre suelos de diferente calidad. Esos datos reforzarían la hipótesis que considera las estelas como hitos territoriales asociados a la movilidad y ubicados en terrenos de paso entre zonas con diferentes recursos agropecuarios.

La aparente falta de relación con los poblados previamente señalada también podría estar influida por la escasez de prospecciones arqueológicas en las cercanías de los lugares de aparición de las estelas: a día de hoy solo se ha aplicado esta metodología en dos estudios publicados (García Sanjuán et al. 2006; Celestino Perez et al. 2012). Otro factor distorsionador podrían ser los estudios sobre estelas que no han tenido en cuenta la información disponible sobre los asentamientos ya conocidos y ubicados en sus cercanías. Además hasta el presente apenas se han efectuado intervenciones arqueológicas extensivas en asentamientos del Bronce Final ubicados en el 
Suroeste, por lo que su conocimiento es parcial. Esto supone una limitación de primera magnitud tanto para estudiar la organización de la región durante este período, incluyendo la localización de las estelas, como para valorar su posible función territorial. En multitud de publicaciones se ha teorizado sobre la organización territorial del Suroeste durante el Bronce Final (Pérez Macías 1983; Gómez Toscano 1997, 2006; Pavón Soldevila 1998; Celestino Pérez 2001: 59-67; Ferrer Albelda y Bandera Romero 2007), pero son escasos los estudios espaciales que la han analizado por medio de técnicas estadísticas como, p. ej., el emprendido en Sierra Morena occidental (García Sanjuán y Hurtado Pérez 1998; García Sanjuán 1999). Sería recomendable prestar mayor atención en el futuro a los asentamientos de este período y a la estructuración y organización del territorio en torno a los mismos, si se quiere comprender la posible función territorial de las estelas en un contexto socioeconómico y territorial de mayor amplitud.

En conclusión, se puede decir que los resultados de este estudio son consistentes con la hipótesis según la cual las estelas podrían haber servido como marcadores territoriales o paisajísticos y en relación con lugares de paso, límites y fronteras (Galán Domingo 1993; García Sanjuán et al. 1996). Ello no excluye la posibilidad de que las estelas hubiesen adquirido también una funcionalidad funeraria, aunque a día de hoy las evidencias son escasas (Harrison 2004: 43) y apuntan a su reutilización durante la Edad del Hierro con esta finalidad (Díaz-Guardamino Uribe 2012). De hecho, este uso diacrónico es una dificultad adicional para estudiar estos monumentos (Díaz-Guardamino Uribe 2010). Este estudio en ningún caso soluciona la controversia en torno a la funcionalidad de las estelas, pero sin duda abre nuevas líneas de trabajo y de análisis que no deberían ser minusvaloradas en el futuro.

\section{BIBLIOGRAFÍA}

Almagro Basch, M. 1966: Las estelas decoradas del Suroeste Peninsular. Bibliotheca Praehistorica Hispana VIII, CSIC. Madrid.

Barceló Álvarez, J. A. 1991: Arqueología, Lógica y Estadistica: Un Análisis de las Estelas de la Edad del Bronce en la Península Ibérica. Universidad Autónoma de Barcelona. Barcelona.

Celestino Pérez, S. 2001: Estelas de guerrero y estelas diademadas. La Precolonización y formación del mundo tartésico. Ediciones Bellaterra. Barcelona.

Celestino Pérez, S. y Salgado Carmona, J. A. 2011: "Nuevas metodologías para la distribución espacial de las estelas del Oeste peninsular". En R. Vilaça (ed.): Estelas e estátuas-menires: da Pré à Protohistória. Actas das IV Jornadas Raianas (Sabugal 2009): 417-448. Sabugal.

Celestino Pérez, S.; Mayoral Herrera, V.; Salgado Carmona, J. A. y Cazorla Martín, R. 2012: "Stelae Iconography and landscape in the Southwest of the Iberian Peninsula". En T. Moore y X. L. Armada (eds.): Western Europe in the First Millenium $B C$. Crossing the divide. Oxford University Press. Oxford: 135-152.

Crema, E. R.; Bevan, A. y Lake, M. W. 2010: "A Probabilistic Framework for Assessing Spatio-Temporal Point Patterns in the Archaeological Record". Journal of Archaeological Science 37: 1118-1130.

Conolly, J. y Lake, M. 2006: Geographical information systems in archaeology. Cambridge University Press. Cambridge.

Díaz-Guardamino Uribe, M. 2010: Las estelas decoradas en la Prehistoria de la Península Ibérica. Tesis doctoral, Universidad Complutense de Madrid. Madrid. http://eprints.ucm.es/11070/1/T32200.pdf (consulta 12-X-2012)

Díaz-Guardamino Uribe, M. 2012: "Estelas decoradas del Bronce Final en la Península Ibérica: datos para su articulación cronológica”. En J. Jiménez Ávila (ed.): Sidereum Ana II. El río Guadiana en el Bronce Final (Mérida, 2008). Anejos de Archivo Español de Arqueología 42, CSIC, Instituto de Arqueología de Mérida, Junta de Extremadura. Mérida: 389-416.

Domínguez Berenjeno, E. y Cervera Pozo, L. 2009: “Actividad Arqueológica Puntual 'Prospección del Término Municipal de Ecija (Sevilla)' (2002-2003)'. Anuario Arqueológico de Andalucía 2004, 1: 3220-3240.

Domínguez de la Concha, C.; González Bornay, J. M. y Hoz Bravo, J. de 2005: Catálogo de Estelas Decoradas del Museo Arqueológico Provincial de Badajoz. Junta de Extremadura. Badajoz.

Durán Recio, V. 1990: Evolución del problema del poblamiento antiguo en el término municipal de Écija. Sevilla Editorial Gráficas Sol. Écija.

Fábrega-Álvarez, P.; Fonte, J. y González García, F. J. 2011: "Las sendas de la memoria. Sentido, espacio y reutilización de las estatuas-menhir en el noroeste de la Península Ibérica". Trabajos de Prehistoria 68 (2): 313-330.

Ferrer Albelda, E. 2007: Arqueología en Marchena: El poblamiento antiguo y medieval en el valle medio del río Corbones. Universidad de Sevilla. Sevilla.

Ferrer Albelda, E. y Bandera Romero, M. ${ }^{a}$ L. de la 2007: "Santuarios, aldeas y granjas: El poblamiento

Trab. Prehist., 70, N. ${ }^{\circ}$ 1, enero-junio 2013, pp 76-94, ISSN: 0082-5638 doi: $10.3989 /$ tp.2013.12103 
durante el Bronce Final y el Período Orientalizante". En E. Ferrer Albelda (ed.): Arqueología en Marchena: el poblamiento antiguo y medieval en el valle medio del río Corbones. Universidad de Sevilla. Sevilla: 45-88.

Ferrer Albelda, E.; Oria Segura, M.; García Vargas, E.; Chaves Tristán, F. y Bandera Romero, $\mathrm{M}^{\mathrm{a}}$ L. de la 2001: "Informe de la prospección arqueológica superficial del término municipal de Marchena (Sevilla)". Anuario Arqueológico de Andalucía 1998 II. Actividades de Urgencia: 1032-1046.

Galán Domingo, E. 1993: Estelas, Paisajes y territorio en el Bronce Final del Suroeste de la Península Ibérica. Complutum Extra 3, Universidad Complutense de Madrid. Madrid.

Galán Domingo, E. 2008: "Historias de gentiles damas y poderosos guerreros: trascendiendo el mito de las estelas del Suroeste". En C. Cacho, R. Maicas, J. A. Martos y M. I. Martínez Navarrete (eds.): Acercándonos al Pasado. Prehistoria en 4 Actos. Museo Arqueológico Nacional, Ministerio de Cultura. Madrid. http://man.mcu.es/museo/JornadasSeminarios/acercandonos_al_pasado.html (consulta 12-X-2012).

García Fernández, F. J. 2003: El poblamiento turdetano en el Bajo Guadalquivir. Universidad de Sevilla. Sevilla.

García Sanjuán, L. 1999: Los orígenes de la estratificación social: patrones de desigualdad en la Edad del Bronce del suroeste de la Península Ibérica (Sierra Morena Occidental c. 1700-1100 a.n.e./2100-1300 A.N.E.). British Archaeological Reports, International Series 823, Archaeopress. Oxford.

García Sanjuán, L. 2010: "The warrior stelae of the Iberian South-west. Symbols of power in ancestral landscapes". En T. Moore y X. L. Armada Pita (eds.): Atlantic Europe in the First Millennium $B C$ : Crossing the Divide. Oxford University Press. Oxford: 1-16.

García Sanjuán, L. y Hurtado Pérez, V. 1998: “La dinámica de poblamiento en la estribación occidental de Sierra Morena durante la Edad del Bronce (c. 1700-1000 a.n.e.)". En L. García Sanjuán (eds.): La Traviesa. Ritual Funerario y jerarquización social en la comunidad de la Edad del Bronce de Sierra Morena Occidental. Spal Monografías 1, Universidad de Sevilla, Sevilla: 35-100.

García Sanjuán, L.; Wheatley, D. W.; Fábrega Álvarez, P.; Hernández Arnedo, M. J. y Polvorinos del Río, A. 2006: "Las estelas de guerrero de Almadén de la Plata (Sevilla). Morfología, tecnología y contexto". Trabajos de Prehistoria 63 (2): 135-152.
Gómez Toscano, F. 1997: El final de la Edad de Bronce entre el Guadiana y el Guadalquivir: el territorio y su ocupación. Universidad de Huelva. Huelva.

Gómez Toscano, F. 2006: "El final de la Edad del Bronce entre el Guadiana y el Guadalquivir: síntesis histórico-arqueológica según las más recientes evidencias". Madrider Mitteilungen 47: 24-42.

Harrison, R. 2004: Symbols and Warriors. Images of the European Bronze Age. Western Academic \& Specialist Press. Bristol.

Hodder, I. y Orton, C. 1989: Spatial Analysis in Archaeology Cambridge University Press. Cambridge.

Murillo Redondo, J. F.; Morena López, J. A. y Ruiz Lara, D. 2005: "Nuevas estelas de guerrero procedentes de las provincias de Córdoba y de Ciudad Real". Romula 4: 7-46.

Murrieta Flores, P. A.; Wheatley, D. W. y García Sanjuán, L. 2009: "Movilidad y vías de paso en los paisajes prehistóricos: megalitos y vías pecuarias en Almadén de la Plata (Sevilla, España)". En V. Mayoral Herrera y C. Celestino Pérez (ed.): Tecnologías de información geográfica y análisis arqueológico del territorio. Actas del V Simposio Internacional de Arqueología de Mérida (2007). Anejos del Archivo Español de Arqueología 49, CSIC, Instituto de Arqueología de Mérida, Junta de Extremadura. Mérida: 411-423.

Nocete Calvo, F. 1994: Las formación del estado en las campiñas del Alto Guadalquivir (3000-1500 a.n.e.): análisis de un proceso de transición. Universidad de Granada. Granada.

Pavón Soldevila, I. 1998: El tránsito del II al I Milenio a. C. en las cuencas medias de los ríos Tajo y Guadiana: la Edad del Bronce. Universidad de Extremadura. Cáceres.

Pérez Macías, J. A. 1983: "Introducción al Bronce final en el noroeste de la provincia de Huelva". Habis 14: 207-238.

Ruiz-Gálvez Priego, M. ${ }^{a}$ L. 1995: "El significado de la Ría de Huelva en el contexto de las relaciones de intercambio y de las transformaciones producidas en la transición Bronce Final/Edad del Hierro". En $\mathrm{M}^{\mathrm{a}} \mathrm{L}$. Ruiz-Gálvez Priego (ed.): Ritos de paso y puntos de paso: la ría de Huelva en el mundo del Bronce Final Europeo. Complutum Extra 5, Universidad Complutense de Madrid. Madrid: 129-156.

Shennan, S. 1988: Quantifying Archaeology. Edinburgh University Press. Edinburgh.

Wheatley, D. y Gillings, M. 2002: Spatial technology and archaeology: the archaeological applications of GIS. Taylor and Francis. London. 